Prepared for the U.S. Department of Energy

under Contract DE-AC05-76RL01830

\title{
Measurements with the PNNL Density Sensor aboard the Essayons, July 2009
}

MS Greenwood

September 2009

\section{Pacific Northwest}

NATIONAL LABORATORY

Proudly Operated by Battelle Since 1965 


\title{
DISCLAIMER
}

This report was prepared as an account of work sponsored by an agency of the United States Government. Neither the United States Government nor any agency thereof, nor Battelle Memorial Institute, nor any of their employees, makes any warranty, express or implied, or assumes any legal liability or responsibility for the accuracy, completeness, or usefulness of any information, apparatus, product, or process disclosed, or represents that its use would not infringe privately owned rights. Reference herein to any specific commercial product, process, or service by trade name, trademark, manufacturer, or otherwise does not necessarily constitute or imply its endorsement, recommendation, or favoring by the United States Government or any agency thereof, or Battelle Memorial Institute. The views and opinions of authors expressed herein do not necessarily state or reflect those of the United States Government or any agency thereof.

\author{
PACIFIC NORTHWEST NATIONAL LABORATORY \\ operated by \\ BATTELLE \\ for the \\ UNITED STATES DEPARTMENT OF ENERGY \\ under Contract DE-AC05-76RL01830 \\ Printed in the United States of America \\ Available to DOE and DOE contractors from the \\ Office of Scientific and Technical Information, \\ P.O. Box 62, Oak Ridge, TN 37831-0062; \\ ph: (865) 576-8401 \\ fax: (865) 576-5728 \\ email: reports@adonis.osti.gov

\footnotetext{
Available to the public from the National Technical Information Service, U.S. Department of Commerce, 5285 Port Royal Rd., Springfield, VA 22161 ph: (800) 553-6847 fax: (703) 605-6900

email: orders@ntis.fedworld.gov

online ordering: http://www.ntis.gov/ordering.htm
}

This document was printed on recycled paper. 


\section{Measurements with the PNNL Density Sensor aboard the Essayons, July 2009}

MS Greenwood

September 2009

Prepared for

the U.S. Department of Energy

under Contract DE-AC05-76RL01830

Pacific Northwest National Laboratory

Richland, Washington 99352 



\section{Summary}

On July 9, 2009, the Pacific Northwest National Laboratory (PNNL) ultrasonic sensor obtained density data for the sand slurry dredged near the mouth of the Columbia River by the Essayons. The objective of these measurements was to compare the data from the ultrasonic sensor with that obtained by the radioactive sensor, currently in use. The U. S. Corps of Engineers is interested in a sensor technology capable of competing with the radioactive sensor to ease regulatory concerns. The average density obtained during the data acquisition was smaller than the expected value of $1.3 \mathrm{~g} / \mathrm{cm}^{3}$. Further investigation showed that the radioactive sensor measured a density of $1.11 \mathrm{~g} / \mathrm{cm}^{3}$ for the calibration liquid, but the code was set up with the density of seawater of $1.025 \mathrm{~g} / \mathrm{cm}^{3}$. This mismatch partially explained the low density value. However, the conclusion was that, while the basic data is very good, the current interpretation of that data needed modification. A new model has been developed that describes how the ultrasound interacts with the sand particles in the slurry. The new model requires the evaluation of a constant $\mathrm{k}_{\text {surf }}$ from a laboratory experiment. This was carried out at PNNL using sand obtained from the Oregon coast during a previous visit to the Essayons. A value for $\mathrm{k}_{\text {surf }}$ was determined with an error of $\pm 10 \%$, which, of course, is too large. For future work, another design is proposed and a more accurate value is expected. Measurements with the refractometer showed the effects of tides. That is, in the morning the density of the seawater was very close to that for fresh water, while in the afternoon, the density was due to salt water. The results of the analysis showed that the average density of the sand slurry varies between 1.230 and $1.235 \mathrm{~g} / \mathrm{cm}^{3}$. The last section of this report discusses in detail improvements for future development. The conclusion is that, once these improvements have been made, the performance of PNNL density sensor will compete very favorably with that of the radioactive sensor. 



\section{Acknowledgments}

The author wishes to thank Captain Nyberg and the staff of the Essayons for their hospitality during our visit in July. It was greatly appreciated. 



\section{Contents}

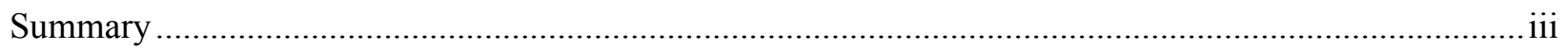

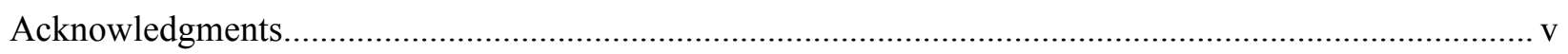

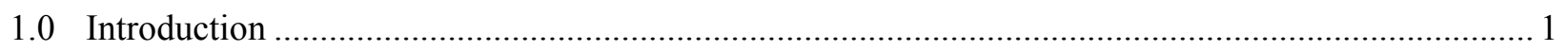

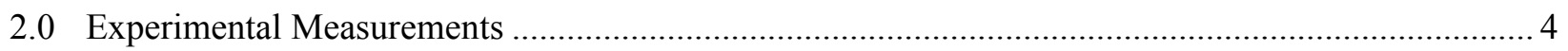

3.0 Model for Determining the Relationship between the Reflection Coefficient and the Density

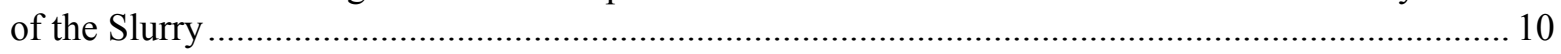

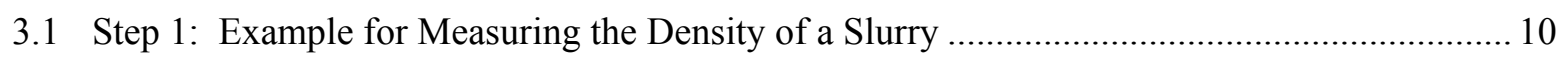

3.2 Step 2: Using an Example to Calculate the Reflection Coefficient........................................... 12

3.3 Step 3: Effect of Surface of the Sand Grains........................................................................... 15

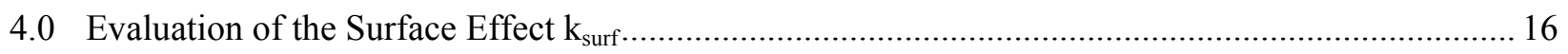

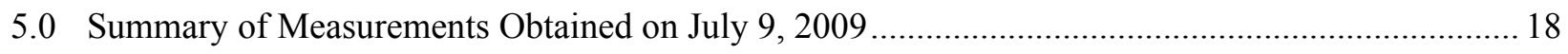

5.1 Measurements with Data Acquisition System..................................................................... 18

5.2 Density Measurements Using Radioactive Sensor............................................................... 18

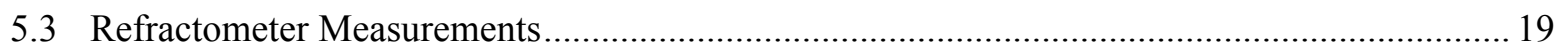

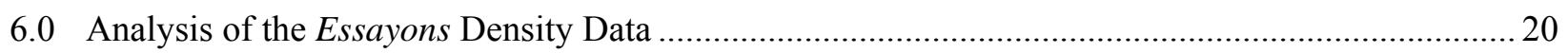

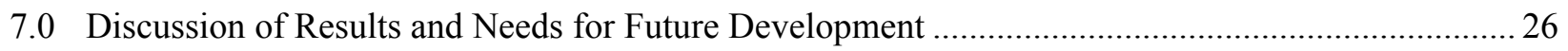

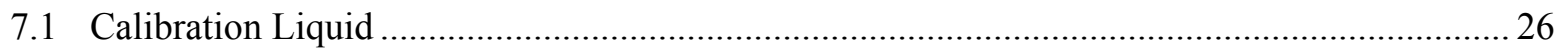

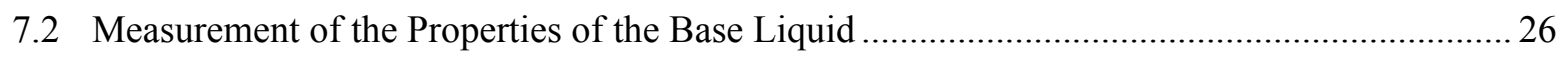

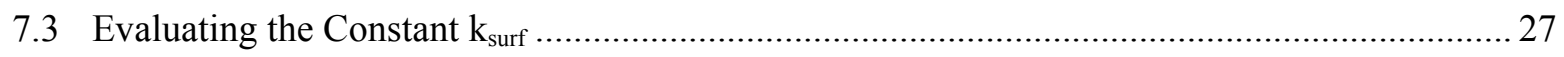

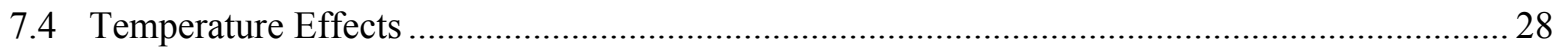

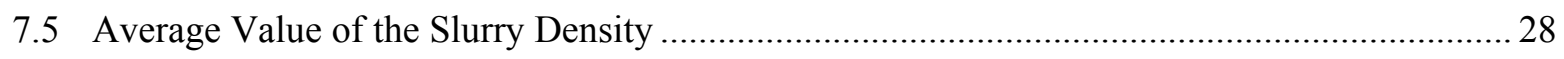

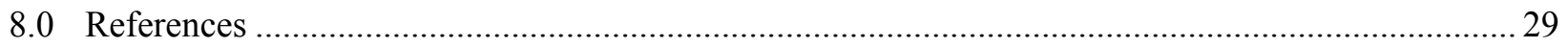




\section{Figures}

1 Results of Using a New Model to Interpret the Measurements of the Ultrasonic Sensor.................... 2

2 Comparison of the Data Obtained from the Ultrasonic Sensor with that from the Radioactive

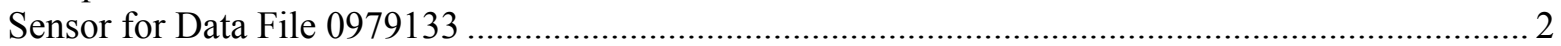

3 Original Output Obtained by the Data Acquisition System for File 0979133 _.................................. 3

4 Photograph of the Transducers Placed Close to the Radioactive Density Sensor on the

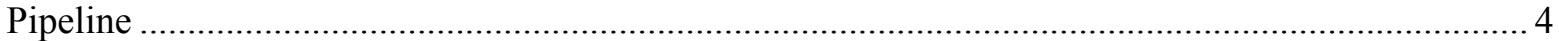

5 Photograph Showing Margaret Greenwood Operating the PNNL Data Acquisition System...............5

6 Schematic Diagram of Transducer Mounted on Pipeline Wall and the Multiple Reflections

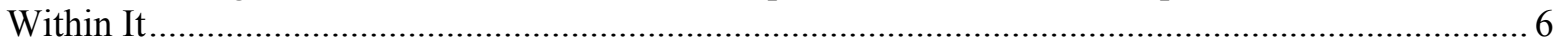

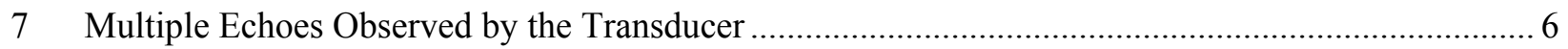

8 Comparison of Each Echo for a Slurry with that for the Calibration Liquid ...................................... 8

9 Schematic Drawing Showing the Formation of a Sand-Water Slurry ............................................. 11

10 Two-Dimensional View of Water and Sand Block in Direct Contact with Section of Steel

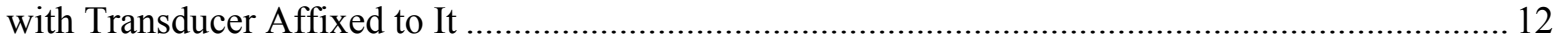

11 Magnified View of Part of Figure 10 to Illustrate Interaction of Ultrasound with Base of the

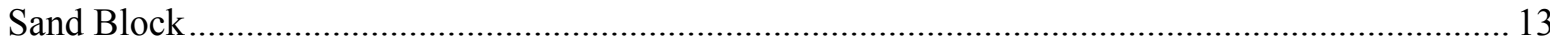

12 Illustration of the Experimental Data that would be Obtained when the Distance between the Base of the Sand and Steel Surface is Very Close to Zero .............................................................. 14

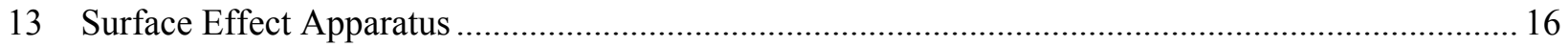

14 Data Obtained from the Radioactive Sensor as a Function of Time ............................................... 19

15 Average Values Obtained by Dividing 3000 Values into Various Segments and Calculating

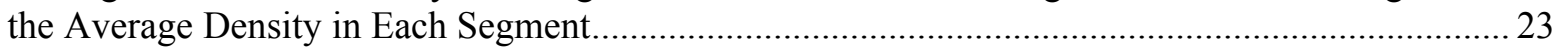

16 Average Value of the Density Obtained by Dividing the 3000 Values into 6 Segments and

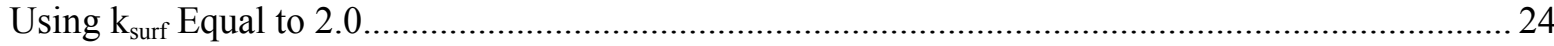

17 Average Value of the Density for 6 Segments Using File 09791544 ............................................ 24

18 Slurry Density When Dredging Efficiency was Reduced for File 09791759 _..................................25

19 Schematic Diagram of Base-Liquid Sensor for Measuring the Density and Velocity of Sound in the Base Liquid 


\section{Tables}

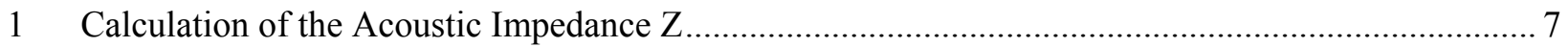

2 Reflection and Transmission Coefficients .......................................................................... 7

3 Evaluation of Parameters Required for the Calculation of the Density .......................................... 11

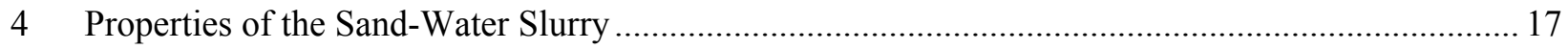

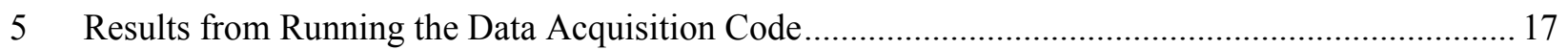

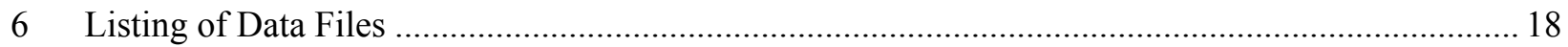

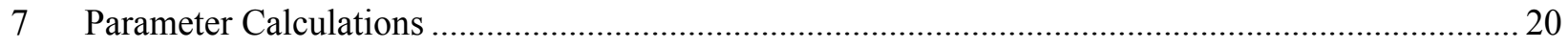

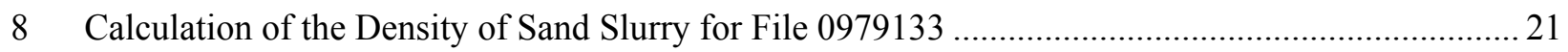





\subsection{Introduction}

On July 9, 2009, the Pacific Northwest National Laboratory (PNNL) ultrasonic sensor obtained density data for the sand slurry dredged near the mouth of the Columbia River by the Essayons. Dr. Margaret S. Greenwood operated the ultrasonic sensor. Readings for the radioactive sensor and the refractometer, located on the Bridge, were also obtained.

As the data acquisition was occurring, Greenwood saw that the density values appeared to be low. However, the data for several runs was remarkably similar. A water calibration run was taken at the start of the day and was used to analyze and obtain the density values. At the end of the day, a water calibration was taken again and it agreed very well with the one taken initially. The data appeared to be quite sensitive to changes in the slurry, and there was a wide range of density values. The system was set up so that the information from a single short ultrasonic pulse is obtained. Since the signal is recorded in only 0.06 seconds, the system measures the density as a function of time. Three density values were obtained per second. An average over a number of values is obtained to represent the density that would be reported to the ship's data acquisition system in future development.

The conclusion was that the basic data obtained by the PNNL sensor was very good, but that the current interpretation of that data needed modification. A similar conclusion can be reached by reviewing the laboratory data reported in the Letter Report of October 2007. Indeed, a new model for interpreting the data has been developed and the results are shown in Figure 1 and Figure 2. Figure 1 shows the density data obtained for 3000 points obtained during one run in file 0979133 . Figure 2 shows the average for 15 segments, where the data are averaged over 200 points. The data acquisition system captures the time for each data point. In Figure 2 the average density is plotted versus the time at the midpoint of the segment for data file 0979133. The data for the radioactive sensor was obtained by recording values observed on the Bridge. The value of $\mathrm{k}_{\text {surf }}$ is determined experimentally to be $1.3066 \pm$ 0.1340 in Section 4. The results for the upper limit are shown by the square symbols in Figure 2. Given the large uncertainty in $\mathrm{k}_{\text {surf }}$, the results are also determined for $\mathrm{k}_{\text {surf }}$ equal to 2.2 and shown by the triangle symbols in Figure 2. However, there were a number of uncertainties in the measurements and these will be explained in later sections. These results can be compared with that obtained during the data acquisition, as shown in Figure 3.

The values of the slope in Figure 3 are expected to be negative, but many positive values were obtained. This problem was resolved when the readings of the radioactive sensor showed a reading of $1.11 \mathrm{~g} / \mathrm{cm}^{3}$ while the calibration was being obtained. Because the data acquisition code used the density of seawater as $1.025 \mathrm{~g} / \mathrm{cm}^{3}$, the disparity of these two values resulted in the positive slope. Some small amount of sand must have been in the seawater during the calibration. The way to eliminate such disparities in the future is discussed at the end of the report.

Section 2 describes the basic data and defines the reflection and transmission coefficients that are needed to analyze the data according to the new model. 


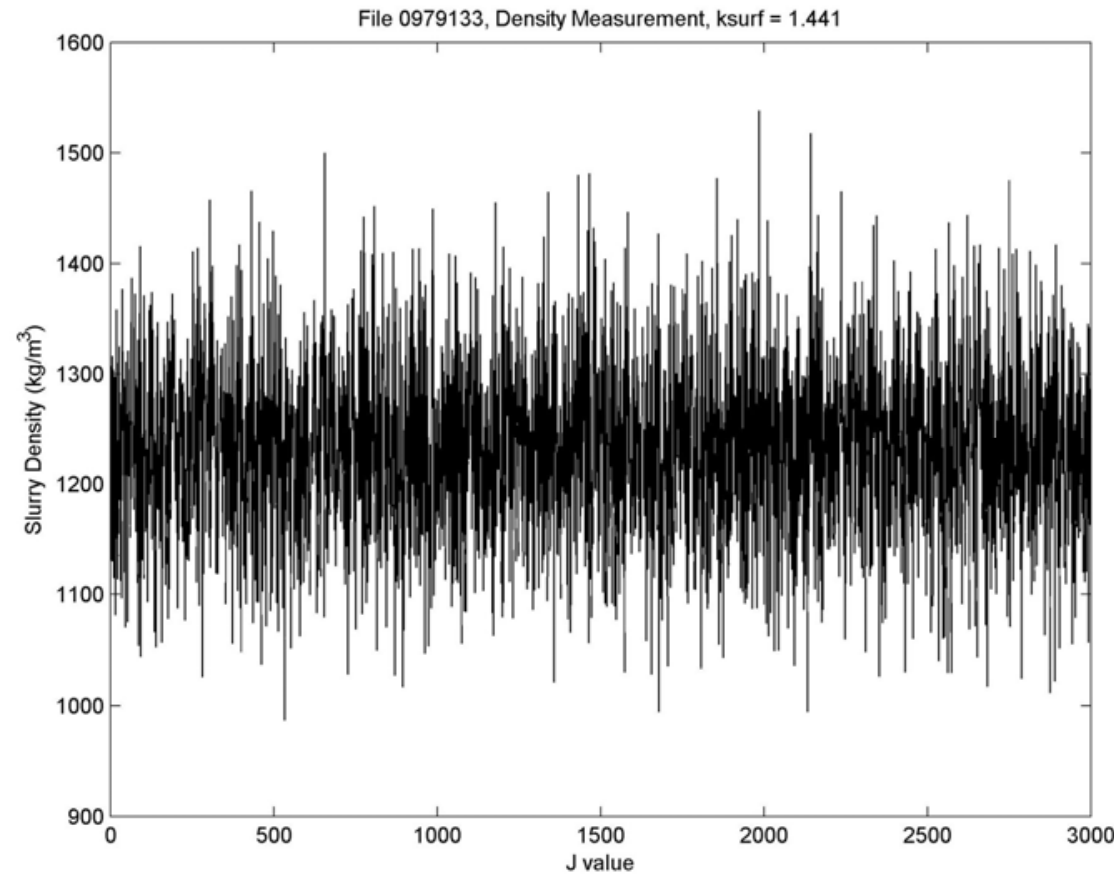

Figure 1. Results of Using a New Model to Interpret the Measurements of the Ultrasonic Sensor. The data obtained in file 0979133 contain 3000 values with each one identified by the J value.

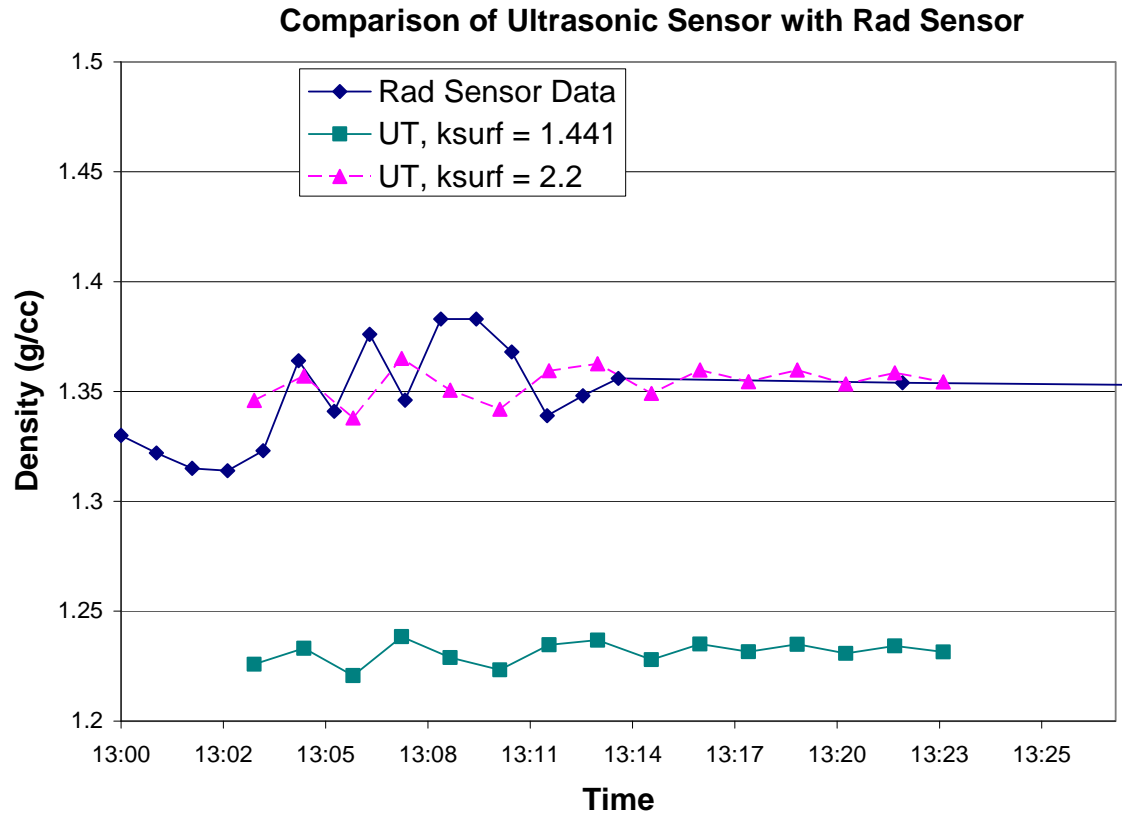

Figure 2. Comparison of the Data Obtained from the Ultrasonic Sensor with that from the Radioactive Sensor for Data File 0979133 

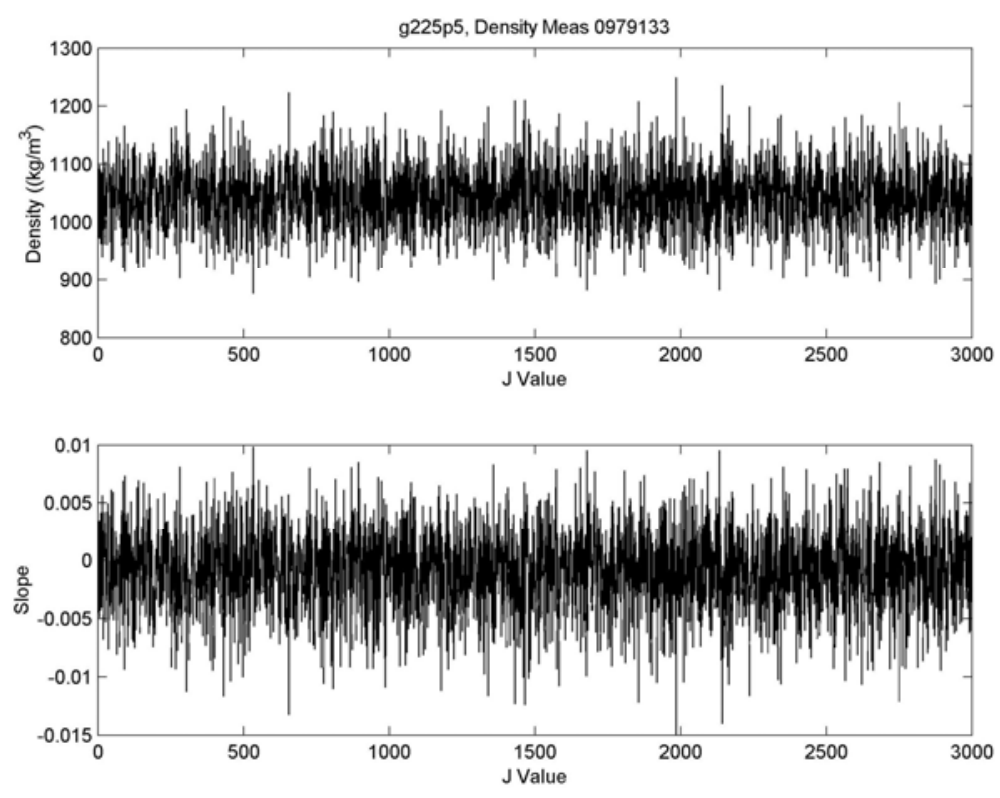

Figure 3. Original Output Obtained by the Data Acquisition System for File 0979133

In Section 3, the model for determining the density of a sand-seawater slurry is discussed in detail. This model is based upon the simple calculations carried out to determine the density of the sand slurry, when the quantities of water and sand are known. This model is then extended to consider how ultrasound interrogates the slurry when the "vessel" is placed upon a steel section (about the same thickness as the wall in the Essayons pipeline) and interrogated with ultrasound. A transducer is affixed below the steel section. When a pulse of ultrasound reaches the steel-slurry interface, most of the ultrasound reflects from the steel-water interface (due to the large size of the sand particles) but some is transmitted into the slurry. The latter interacts with the sand grains near the interface and is scattered by them, some of it back toward the interface. This scattered ultrasound then is transmitted into the steel and travels to the transducer. The returned signal, or echo, at the transducer then consists of two parts: one part due to reflection from the steel-water interface and the second due to scattering from the sand grains.

The model deals with the reflection from a flat surface of a block, where all of the sand is considered compressed into this block. The volume occupied by the block is the same as the volume of the sand in the slurry. Because the reflection or scattering from the sand grains is smaller than that from a flat surface, an additional experiment is needed to compare these two situations.

Section 4 describes how this experiment was performed in the laboratory and a preliminary value of the constant $\mathrm{k}_{\text {surf }}$ was obtained. Additional experiments are needed to obtain a more accurate value.

Section 5 summarizes the measurements obtained and Section 6 describes the results of the analysis using the new model. Section 7 discusses the results and the requirements for future development.

The conclusion is that the PNNL density sensor can be designed to measure the density of a slurry dredged from the ocean floor. Given the uncertainties in the parameters for analysis of the Essayons data, the results are acceptably close to the expected value of the density. 


\subsection{Experimental Measurements}

Several transducers were placed very close to the radioactive sensor on the Essayons, as shown in Figure 4. Preliminary data were obtained for each one, but the data from the $2.25-\mathrm{MHz}$ transducer with a diameter of 0.5 inches was superior and the results from this transducer are presented here. It is the second one from the left with a rectangular shape. The data acquisition system operated by Greenwood is shown in Figure 5. The pulser-receiver that transmits the ultrasound to the transducer is not shown in these photographs. The data acquisition system was one level above the radioactive source and the transducers.

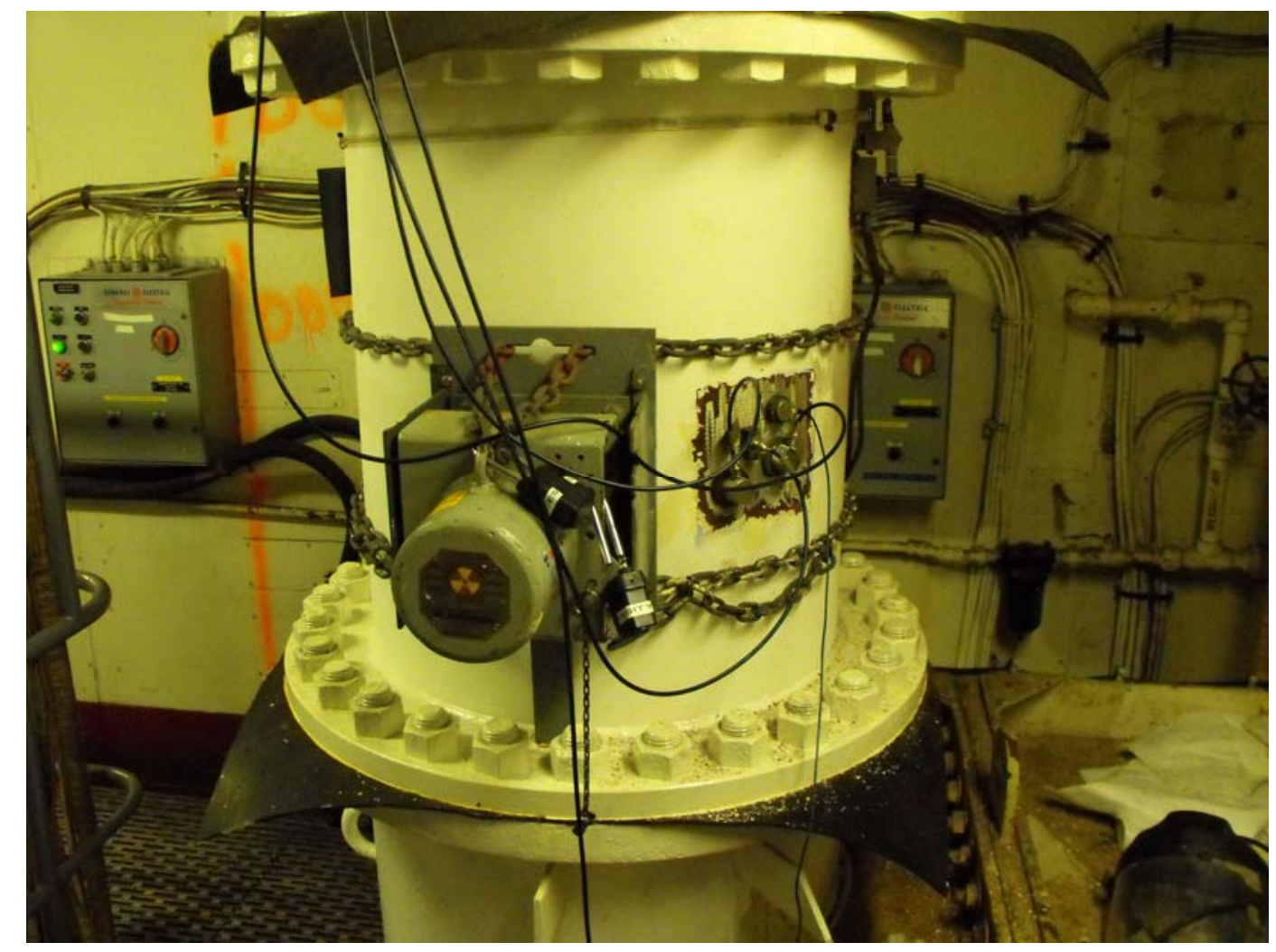

Figure 4. Photograph of the Transducers Placed Close to the Radioactive Density Sensor on the Pipeline 


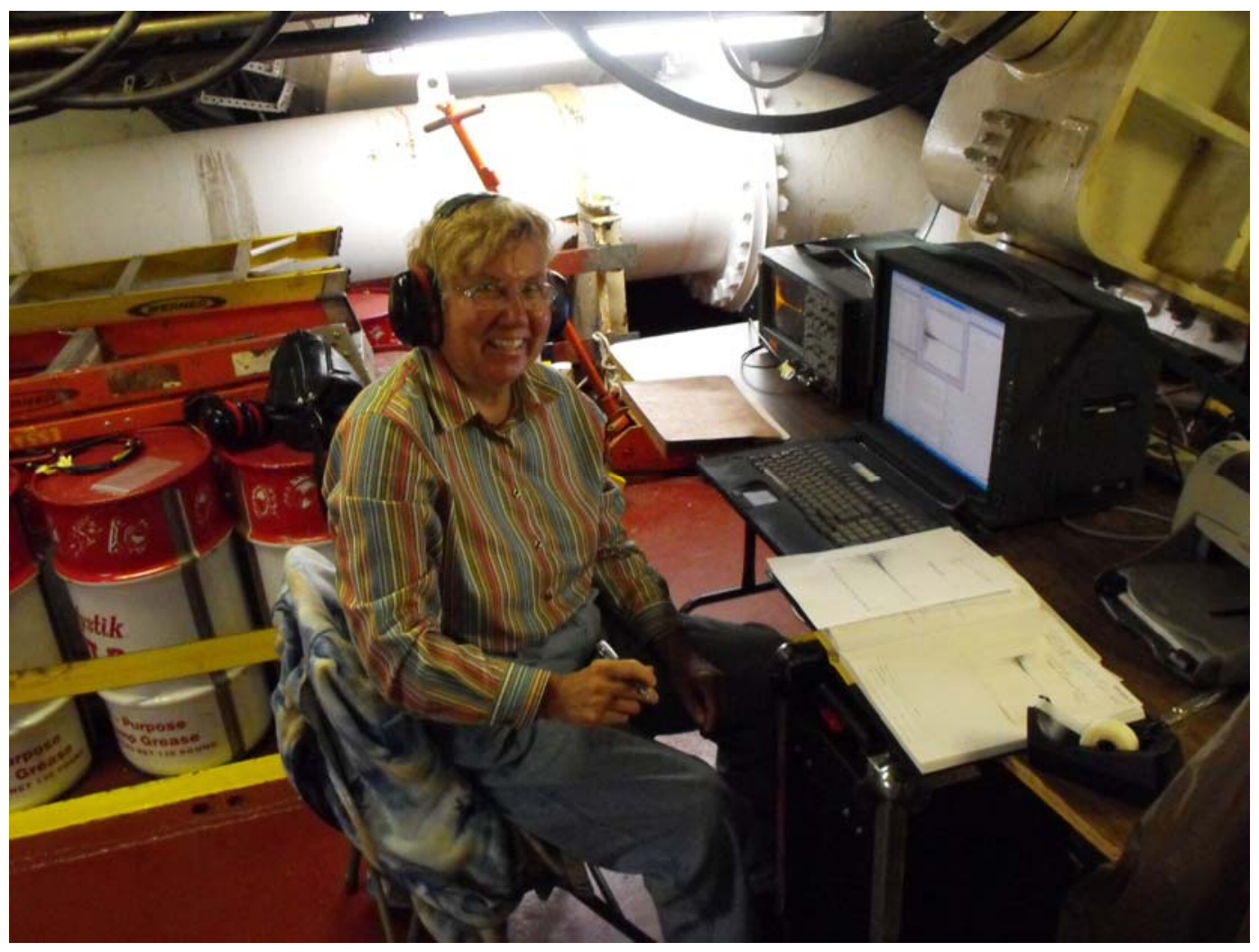

Figure 5. Photograph Showing Margaret Greenwood Operating the PNNL Data Acquisition System

The measurement of the density of the slurry, occurring at the rate of 3 values per second, is based upon the reflection of ultrasound at the interface between the solid and slurry, as shown in Figure 6. A very short pulse of ultrasound is transmitted by the transducer and travels through the steel to the inside wall, where some of it is reflected back to the transducer. Here it is reflected again and so on, so that the pulse of ultrasound makes many echoes between the inside wall and the outside wall. Each time the ultrasound reaches the outside wall, some of it travels to the transducer and produces a so-called echo. The multiple echoes are shown in Figure 7 for data obtained on the Essayons. The time between two adjacent echoes is the time for the sound to make a round trip in the steel.

The ability to determine the density is based upon observation of all of these echoes and determining the reflection coefficient of the slurry. When ultrasound traveling in steel reaches the interface with water, some of the ultrasound is reflected back into the steel and some ultrasound is transmitted into the water. The pressure reflection coefficient is defined as:

$$
\text { Reflection coefficient }=\frac{\text { pressure amplitude of the reflected wave }}{\text { pressure amplitude of the incident wave }}
$$




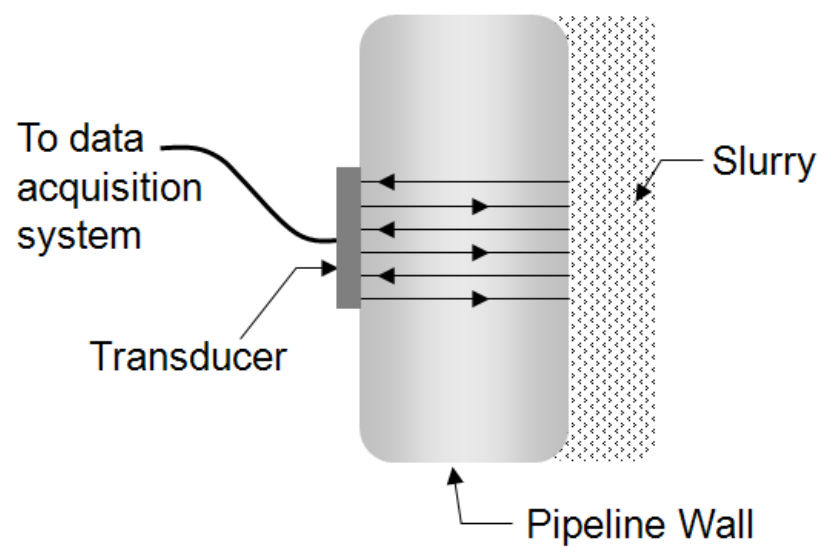

Figure 6. Schematic Diagram of Transducer Mounted on Pipeline Wall and the Multiple Reflections Within It

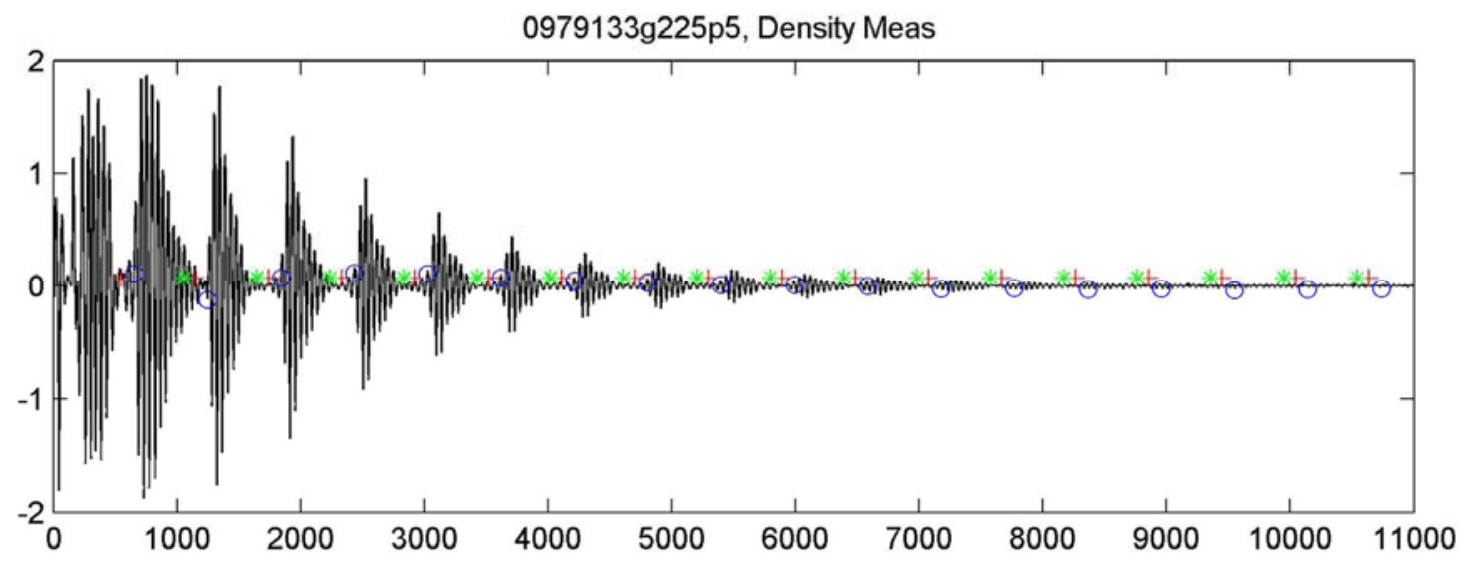

Figure 7. Multiple Echoes Observed by the Transducer. The red plus sign and the green asterisk show the limits of each echo. The small circle indicates the start of the echo.

The transmission coefficient is defined similarly as:

$$
\text { Transmission coefficient }=\frac{\text { pressure amplitude of the transmitted wave }}{\text { pressure amplitude of the incident wave }}
$$

For a sine wave, the amplitude is the height of the peak. The reflection coefficient can have positive or negative value. A negative value means that the wave "flips" about the axis. That is, upon reflection a peak becomes a trough, and vice versa.

The reflection and transmission coefficients are dependent upon the properties of the materials at the interface: the densities and the velocities of sound for both materials at the interface. The acoustic impedance $\mathrm{Z}$ is defined as the product of the density of the material and the velocity of sound in that material. The reflection coefficient $\mathrm{R}$ and the transmission coefficient $\mathrm{T}$ (Krautkrämer and Krautkrämer 1990, pp. 16-18) are defined as follows: 


$$
\begin{aligned}
& R=\frac{Z_{2}-Z_{1}}{Z_{2}+Z 1} \\
& T=\frac{2 Z_{2}}{Z_{1}+Z_{2}}
\end{aligned}
$$

In the above equations, the subscript " 1 " refers to the material in which the incident wave is traveling and the subscript " 2 " refers to the other material at the interface. For example, if a sound wave is traveling in steel and the wave reflects at the interface with water, the subscript " 1 " refers to steel and the subscript "2" refers to water. Table 1 contains values of the acoustic impedance and Table 2, values of the reflection and transmission coefficients.

\begin{tabular}{|c|c|c|c|}
\hline Material & $\begin{array}{l}\text { Density } \\
\left(\mathrm{g} / \mathrm{cm}^{3}\right)\end{array}$ & $\begin{array}{l}\text { Velocity of Sound } \\
(\mathrm{cm} / \mathrm{s})\end{array}$ & $\begin{array}{c}\text { Acoustic Impedance Z } \\
\left(\mathrm{g} / \mathrm{cm}^{2} \mathrm{~s}\right)\end{array}$ \\
\hline Water & 0.998 & $1.482 \times 10^{5}$ & $1.479 \times 10^{5}$ \\
\hline Steel & 7.841 & $5.875 \times 10^{5}$ & $46.070 \times 10^{5}$ \\
\hline Sand & 2.61 & $5.570 \times 10^{5}$ & $14.538 \times 10^{5}$ \\
\hline
\end{tabular}

Table 1. Calculation of the Acoustic Impedance $Z$

Table 2. Reflection and Transmission Coefficients. For simplicity, the factor $10^{5}$ has been eliminated because these factors will cancel out.

\begin{tabular}{lll}
\hline $\begin{array}{l}\text { Reflection coefficient for wave traveling in } \\
\text { steel and reflecting from water }\end{array}$ & & \\
$\quad$ RCstwtr & $(1.479-46.070) /(1.479+46.070)$ & -0.9378 \\
Reflection coefficient for wave traveling in & & \\
water and reflecting from sand & & \\
$\quad$ RCwtrsand & $(14.538-1.479) /(14.538+1.479)$ & 0.8153 \\
$\begin{array}{l}\text { Transmission coefficient for wave traveling in } \\
\text { steel and into water }\end{array}$ & & \\
$\quad$ Tstwtr \\
$\begin{array}{l}\text { Transmission coefficient for wave traveling in } \\
\text { water and into steel }\end{array}$ & $2(1.479) /(46.070+1.479)$ & 0.0622 \\
$\quad$ Twtrst & $2(46.070) /(46.070+1.479)$ & 1.9378 \\
\hline
\end{tabular}

Graphs similar to Figure 7 will show differences between the slurry and water. A precise method to illustrate the differences is to compare the maximum voltage for each echo for a slurry and for water and calculate the following ratio:

$$
\left(\frac{\mathrm{V}_{\text {slurry }}}{\mathrm{V}_{\text {water }}}\right)_{\text {echo \#n }}=\frac{(\text { maximum amplitude for slurry })_{\text {echo\#n }}}{(\text { maximum amplitude for water })_{\text {echo \#n }}}
$$

The next step is to calculate the natural logarithm of $\left(\mathrm{V}_{\text {slurry }} / \mathrm{V}_{\text {water }}\right)_{\text {echo } \# \mathrm{n}}$ : 


$$
\operatorname{Ln}\left(\frac{V_{\text {slurry }}}{V_{\text {water }}}\right)_{\text {echo \#n }}
$$

If, for example, $\mathrm{n}$ ranges from 2 to 12 , then there are 11 values of the quantity shown in Eq. (6). During the measurements on the Essayons, each data set contained 3000 values of the density with each point specified by a $J$ value. The data in Figure 8 corresponds to $J=655$ for the data set in file d0979133.dat. The slope of the line is $-0.01323 \pm 0.00035$, using a best-fit straight-line through the data points with error bars. This is an important quantity because it is used to find the reflection coefficient for the slurry:

$$
\mathrm{RC}_{\text {slurry }}=\mathrm{RC}_{\text {water }} \mathrm{e}^{\text {slope }}
$$

The relationship in Eq. (7) is derived in Greenwood and Bamberger (2004).

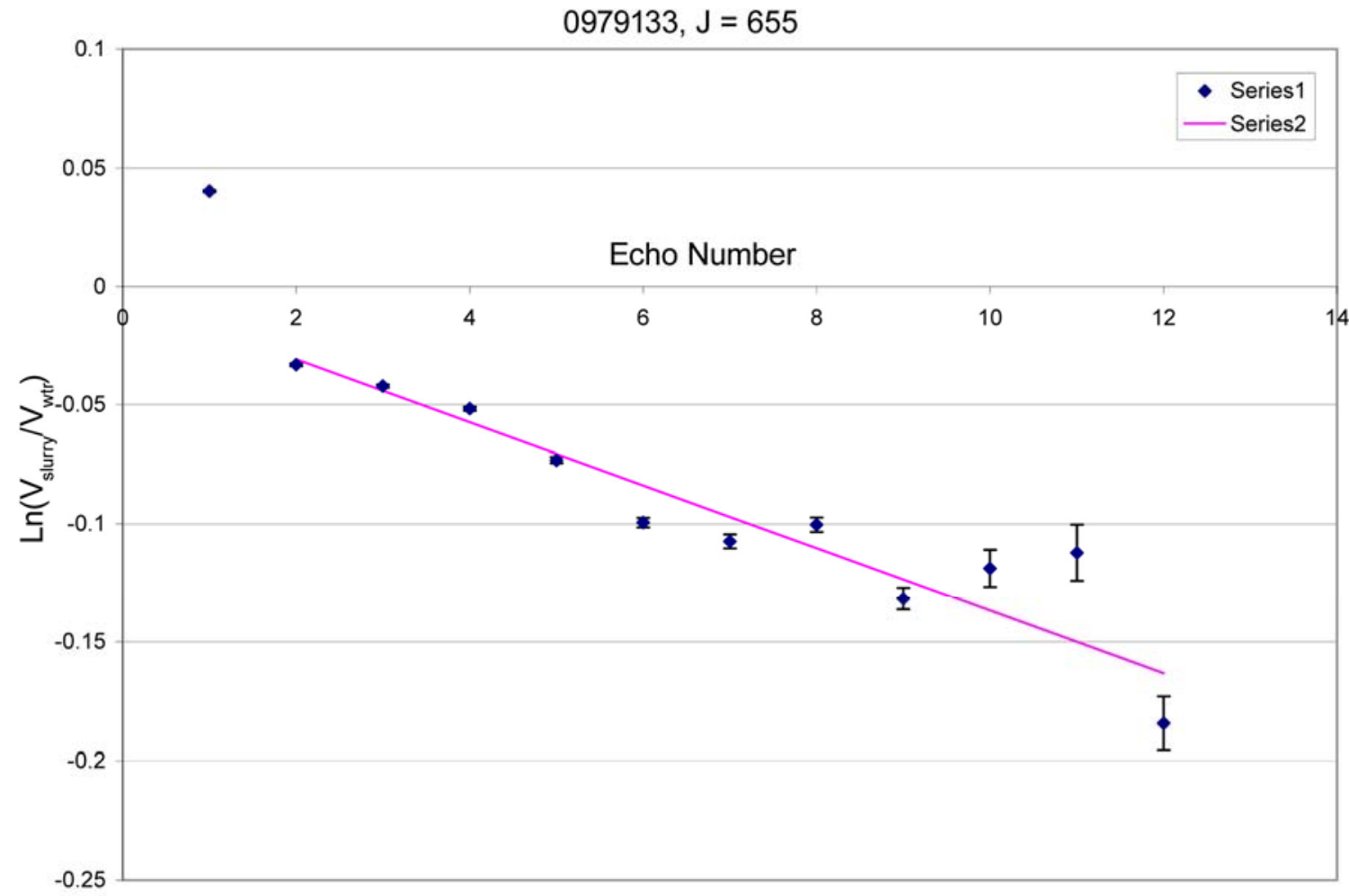

Figure 8. Comparison of Each Echo for a Slurry with that for the Calibration Liquid. This comparison represents the basic experimental data obtained by the ultrasonic sensor.

Because the properties of water are known, its reflection coefficient can be calculated using Eq. (3), as shown in Table 2. Here, water is called the calibration liquid. However, any liquid can be used, provided its density and velocity of sound are known. Air can also be used because ultrasound reflects completely from air, and $\mathrm{RC}_{\text {air }}$ is -1 . However, the data from the Essayons shows positive and negative values of the slope, as can be seen in Figure 3. A negative value of the slope means that the density of the unknown slurry is greater than that for calibration liquid. Similarly, a positive slope means that the 
density of the unknown slurry is less than that of the calibration liquid. As we shall see in a later section, this is important because there are so many positive slopes in the Essayons data.

For the sake of developing Eq. (5), the "maximum voltage" of each echo in Figure 7 was used for the "maximum amplitude" because it is easier to visualize. However, a more accurate procedure is to obtain the fast Fourier transform (FFT) for each echo and to obtain the maximum amplitude of the Fourier transform. In the data acquisition code, this procedure was carried out. The maximum FFT amplitude is, of course, related to the maximum voltage of each echo. For example, if the maximum voltage of the signal is changed by a factor of 2 , the maximum of the FFT is also changed by a factor of 2 . 


\subsection{Model for Determining the Relationship between the Reflection Coefficient and the Density of the Slurry}

The basic information from the experimental data is the slope of the straight line that is obtained from a graph of the natural logarithm of $\left(\mathrm{V}_{\text {slurry }} / \mathrm{V}_{\text {water }}\right)_{\text {echo \#n }}$ plotted versus the echo number. Figure 8 is an example, as discussed above. The reflection coefficient is determined from the slope in Eq. (7). The density of the slurry is obtained by an interpretation of the reflection coefficient:

Experimental Reflection Coefficient $>>>$ Model for Interpreting RC $>>>$ Density of Slurry

In this section, the reverse approach will be taken in three steps: (1) We shall consider an example of a slurry and see how the density of the slurry is defined. (2) A model for the interaction of ultrasound with the slurry will be proposed and the reflection coefficient calculated. (3) We shall consider the effects of the surface of the sand grains upon the measurement of density.

Once we see how to obtain the reflection coefficient for a slurry of known density, the process can be reversed — which is the goal of our measurement — to use the reflection coefficient to find the density.

\subsection{Step 1: Example for Measuring the Density of a Slurry}

A sample of water (in an invisible container) has dimensions of $1.13 \mathrm{~cm} \times 1.13 \mathrm{~cm} \times 1.0 \mathrm{~cm}$, as shown in Figure 9a. The area of the base was chosen to be very close to the area of the 0.5 -in.-diameter transducer used for the Essayons data.

A mass of sand equal to 0.782 grams is added to the container and the height increases to $1.235 \mathrm{~cm}$, as shown in Figure 9b, where the sand has a uniform distribution.

For the sake of the calculation, we shall consider a "thought" experiment in which the water and sand are completely separated, as shown in Figure 9c. While this does not represent exactly the same problem, it is a similar one. It can be used to allow the effect of each component to be considered separately and then the effects can be "added" together, so to speak. In a later section, we will consider the modifications that need to be made in order to adapt these calculations to the slurry. In this case, the sand is completely solid, as well as uniform throughout, conforming to a uniform slurry. Note that the volume of the sand block is the same as that for 0.782 grams of sand. Table 3 shows the numerical calculations that will be used to develop the formulation of the density.

The composition of the slurry is shown in lines 1 through 6 of Table 3 . The density of the slurry, defined as the total mass divided by the total volume, is shown in line 9.

The objective of Figure 9c is to consider each component separately. If one dimension is $0.915 \mathrm{~cm}$, then line 11 shows that the volume is the same as in line 1 . Similarly, the volume of the sand in line 12 is the same as that in line 4. 


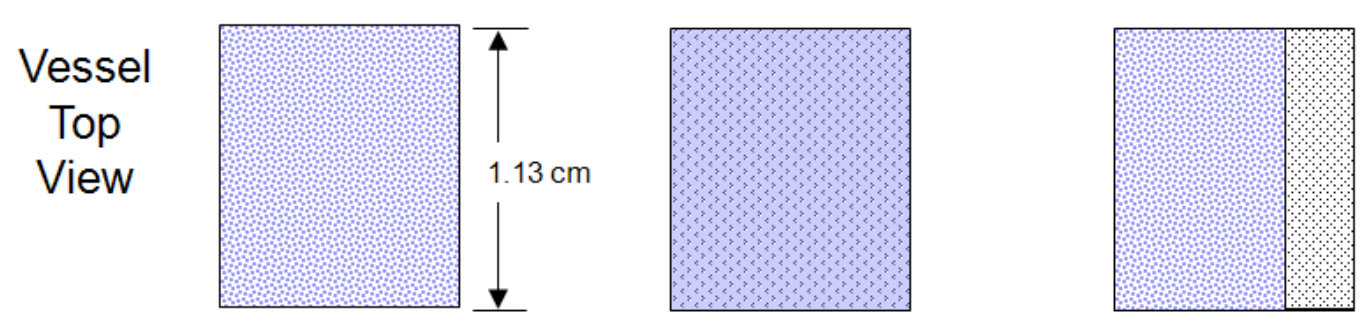

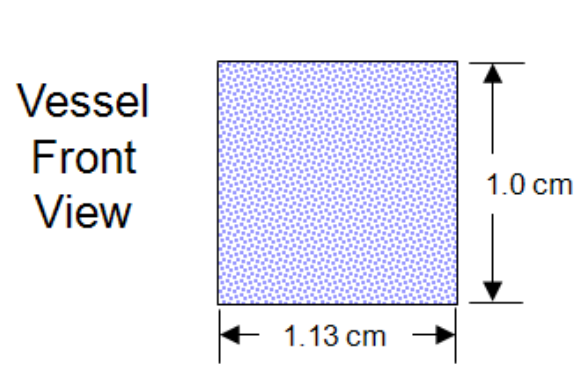

a)

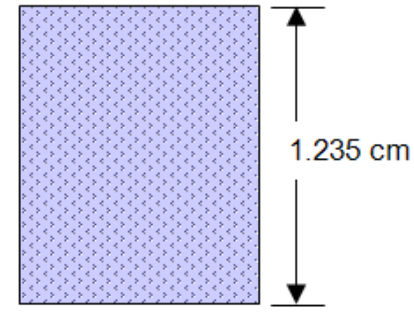

b)

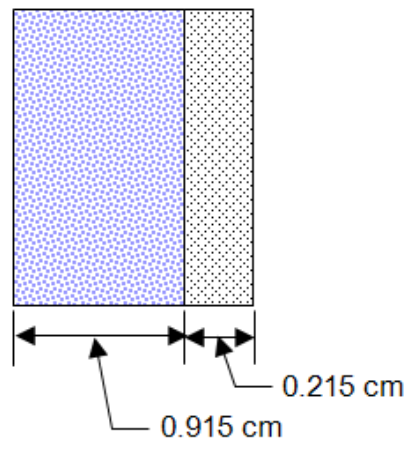

c)

Figure 9. Schematic Drawing Showing the Formation of a Sand-Water Slurry. a) An (invisible) vessel contains 1.274 grams of water. b) 0.782 grams of sand are added to the vessel causing the height to rise to $1.235 \mathrm{~cm}$. c) Sand and water are considered to be separated into two regions.

Table 3. Evaluation of Parameters Required for the Calculation of the Density

\begin{tabular}{lll}
\hline 1 & Volume of water & $1.13 \mathrm{~cm} \times 1.13 \mathrm{~cm} \times 1.0 \mathrm{~cm}=1.277 \mathrm{~cm}^{3}$ \\
2 & Density of water & $0.998 \mathrm{~g} / \mathrm{cm}^{3}$ \\
3 & Mass of water & $1.274 \mathrm{~g}$ \\
4 & Volume of sand & $0.300 \mathrm{~cm}^{3}$ \\
5 & Density of sand & $2.61 \mathrm{~g} / \mathrm{cm}^{3}$ \\
6 & Mass of sand & $0.782 \mathrm{~g}$ \\
7 & Total mass of water and sand & $1.274 \mathrm{~g}+0.782 \mathrm{~g}=2.056 \mathrm{~g}$ \\
8 & Total volume of water and sand & $1.277 \mathrm{~cm}^{3}+0.300 \mathrm{~cm}^{3}=1.577 \mathrm{~cm}^{3}$ \\
9 & Density of slurry & $2.056 \mathrm{~g} / 1.577 \mathrm{~cm}^{3}=1.304 \mathrm{~g} / \mathrm{cm}^{3}$ \\
10 & Alternate method for calculating density in Figure $9 \mathrm{c}:$ & \\
11 & Volume of water & $0.915 \mathrm{~cm} \times 1.235 \mathrm{~cm} \times 1.13 \mathrm{~cm}=1.277 \mathrm{~cm}^{3}$ \\
12 & Volume of sand & $0.215 \mathrm{~cm} \times 1.235 \mathrm{~cm} \times 1.13 \mathrm{~cm}^{3}=0.300 \mathrm{~cm}^{3}$ \\
13 & Area of water at base & $0.915 \mathrm{~cm} \times 1.13 \mathrm{~cm}=1.034 \mathrm{~cm}^{2}$ \\
14 & Area of sand at base & $0.215 \mathrm{~cm} \times 1.13 \mathrm{~cm}=0.243 \mathrm{~cm}^{2}$ \\
15 & Total area of base & $1.13 \mathrm{~cm} \times 1.13 \mathrm{~cm}=1.277 \mathrm{~cm}^{2}$ \\
16 & Fractional area of base for water & $1.034 / 1.279=0.81$ \\
17 & Fraction area of base for sand & $0.243 / 1.279=0.19$ \\
18 & Slurry density & $0.81 \times 0.998+0.19 \times 2.61=1.304 \mathrm{~g} / \mathrm{cm}^{3}$ \\
\hline & & \\
\hline
\end{tabular}


The area of water at the base and that for sand are shown in lines 13 and 14, and the fractional areas are shown in lines 16 and 17. The objective is to show that the density can also be obtained as follows:

$$
\begin{aligned}
\text { Density of slurry } & =(\text { fractional area for water } \times \text { density of water }) \\
& +(\text { fractional area for sand } \times \text { density of sand })
\end{aligned}
$$

This calculation is carried out in line 18 of Table 3 . The result is the same as that in line 9 . We shall see that the concept of fractional areas is very important in Step 2, where ultrasound incident upon each area is considered.

\subsection{Step 2: Using an Example to Calculate the Reflection Coefficient}

First, let us consider placing a sand block on the steel surface shown in Figure 10, without a couplant (liquid or gel) between the block and the steel surface. When the pulse of ultrasound is transmitted, it will travel to the steel interface. The wave will not reflect from the block, it will reflect from the air at the interface and all of the ultrasound will be reflected. That is, no effect of the block will be observed.

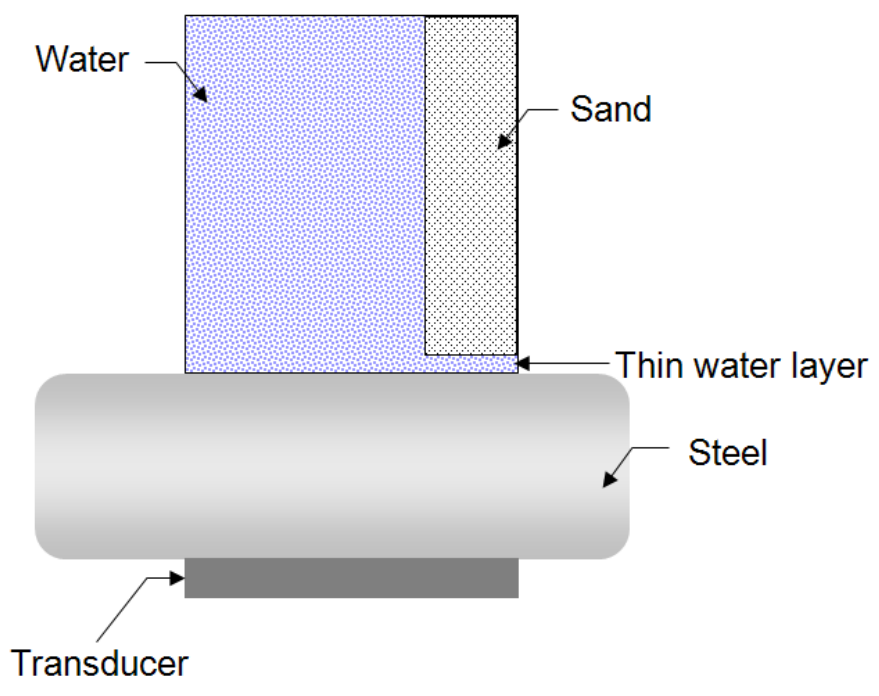

Figure 10. Two-Dimensional View of Water and Sand Block in Direct Contact with Section of Steel with Transducer Affixed to It

Next, we consider the slurry to be in direct contact with the section of steel that is $1.905-\mathrm{cm}$ thick (0.75-in. thick). Affixed to the steel section is a transducer having a frequency of $2.25 \mathrm{MHz}$, which is obviously very similar to the Essayons experiment, with the exception of a square cross section, rather than a circular one. In Figure 10 we consider a two-dimensional view of the slurry in Figure 9c to be in contact with the steel. Below the sand block is a thin coating of water. The water serves a very important function-it couples the block to the steel, just as the water in the actual measurement couples the sand particles to the steel. 
In Figure 11 we consider the sand block separated by a distance L from the steel surface with water between them. When the ultrasound traveling in steel strikes the interface, it encounters water and reflects from it, shown as the downward black arrow. Some ultrasound is transmitted into the water, as shown by the upward red arrow, and travels until it hit the block, where it reflects, as shown by the blue arrow. Then it travels back to the steel, where it is transmitted, as shown by the small, black, downward arrow. Both waves, indicated by the two black downward arrows, will travel to the transducer and be recorded as two signals. The transducer will record a signal from reflection from the steel-water interface and then a short time later $(2 \mathrm{~L} / \mathrm{c})$ the echo from striking the block. These two signals will have opposite phases, due to the negative reflection coefficient for the reflection at the steel-water interface and positive values for interaction with the sand block. However, as the distance $\mathrm{L}$ is decreased, the two signals become very close together. When the distance L is very small, the two signals overlap, leading to destructive interference, which is what we see in the data.

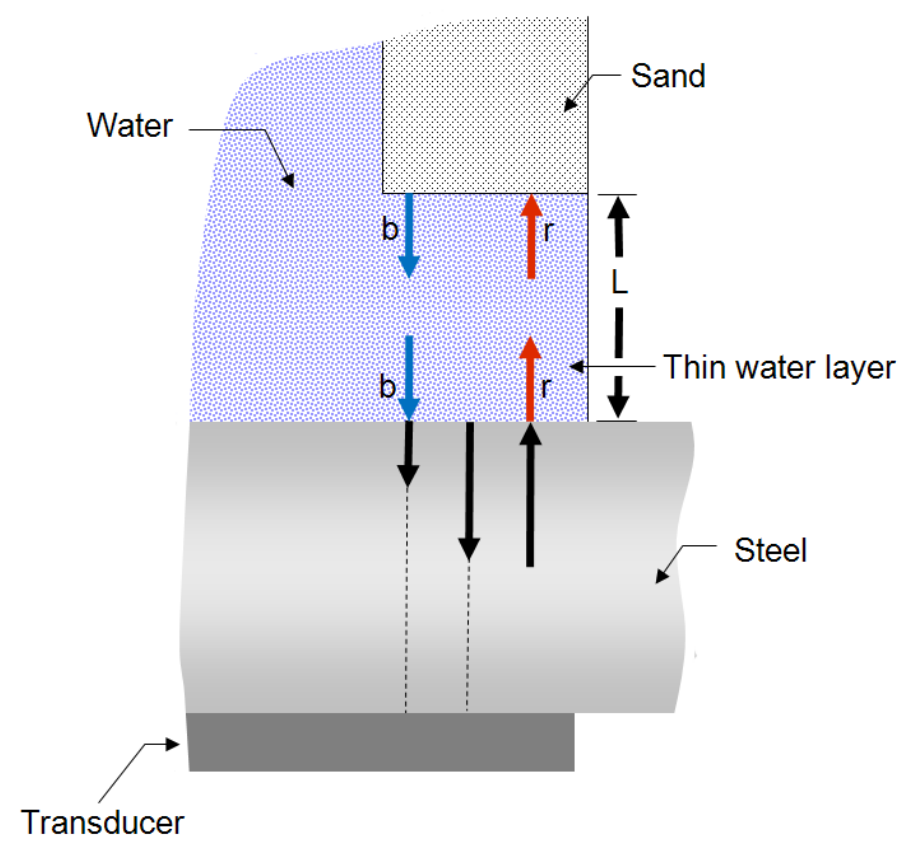

Figure 11. Magnified View of Part of Figure 10 to Illustrate Interaction of Ultrasound with Base of the Sand Block

The total reflection coefficient is based upon the fractional area contribution. Because water covers the entire surface, including the thin layer of water as a couplant to the sand block, the fractional area for water is 1.0. The fractional area for the sand block is 0.19 , as shown in Table 3 , and the reflection and transmission coefficients are given in Table 2 .

$$
\begin{aligned}
\text { RCtotal } & =\text { RCstwtr } \times \text { fractional area for water } \\
& + \text { Tstwtr } \times \text { Rwtrsand } \times \text { Twtrst } \times \text { fractional area for sand block }
\end{aligned}
$$


The important question, of course, is: How does one calculate the reflection coefficient of -0.9191 from experimental data? The first step is to carry out a calibration (often, water), in which the amplitude of each echo is obtained and stored in a file. This is $\mathrm{V}_{\mathrm{wtr}}$ in Eq. (6). The second step is to obtain data for the slurry (water + sand block), in which the amplitude for each echo is again obtained and designated as $\mathrm{V}_{\text {slurry. }}$. The quantity $\operatorname{Ln}\left(\mathrm{V}_{\text {slurry }} / \mathrm{V}_{\text {water }}\right)$ is calculated for each echo and a graph of $\operatorname{Ln}\left(\mathrm{V}_{\text {slurry }} / \mathrm{V}_{\text {water }}\right)$ versus the echo number is plotted. Figure 12 shows the type of data that might be obtained from such a measurement. The data has a slope of -0.0201 . The reflection coefficient for the water calibration is -0.9378 . Use of Eq. (7) yields the RC equal to -0.9191.

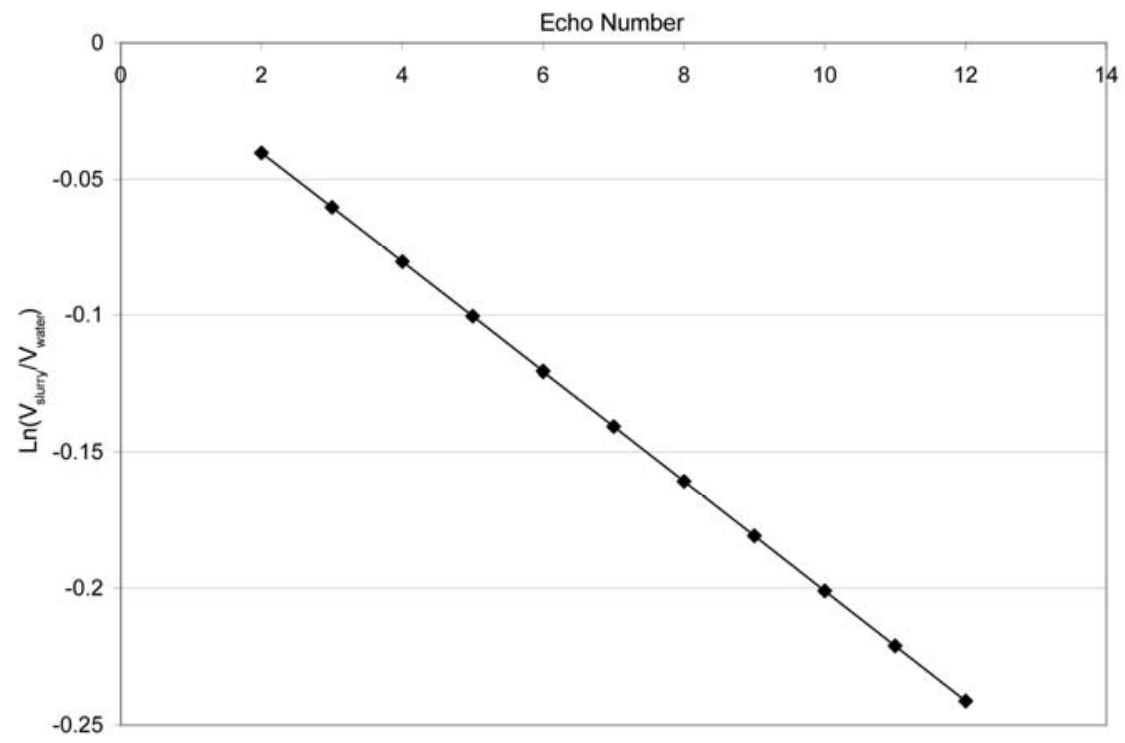

Figure 12. Illustration of the Experimental Data that would be Obtained when the Distance between the Base of the Sand and Steel Surface is Very Close to Zero

The goal of this example is to start with a slurry of known density, calculate the reflection coefficient, and produce a graph similar to Figure 12. The objective, of course, is to reverse this process and obtain the density for a sand-water slurry of unknown concentration.

The results for describing the reflection coefficient in terms of a model and the determination of the density are as follows:

$$
\text { RCtotal }=\text { RCstwtr }+ \text { TstwtrRwtrsandTwtrst } \mathrm{f}
$$

where $\mathrm{f}$ is the fractional area of the sand block.

The density of the slurry is given by

$$
\text { rhoslurry }=(1-\mathrm{f}) \text { rhowater }+\mathrm{f}(\text { rhosand })
$$

where rhoslurry is the density of the slurry and similarly, for rhowater and rhosand. 


\subsection{Step 3: Effect of Surface of the Sand Grains}

When the ultrasound strikes the flat surface of the sand block, the ultrasound strikes the surface perpendicularly and reflects the ultrasound perpendicularly as well. Now we consider the actual situation where sand grains are distributed uniformly through the water, as shown in Figure $9 \mathrm{~b}$. The sand grains will have a larger surface area, and will scatter the ultrasound perpendicularly, and in many other directions as well. Therefore, a smaller amount of ultrasound will be reflected to the transducer. To account for this deficit, $\mathrm{f}_{\exp }$ is defined as the experimental measurement of the fractional surface area of the sand. The quantity $f_{\exp }$ must be multiplied by a constant $\mathrm{k}_{\text {surf }}$ so that it is equivalent to a flat surface. With these definitions, the adjusted reflection coefficient is given by:

$$
\begin{gathered}
\mathrm{f}=\mathrm{k}_{\text {surf }} \mathrm{f}_{\text {exp }} \\
\mathrm{RC}=\mathrm{RCstwtr}+\text { Tstwtr Rwtrsand Twtrst } \mathrm{k}_{\text {surf }} \mathrm{f}_{\text {exp }}
\end{gathered}
$$

And the density of the slurry is given by

$$
\text { Rhoslurry }=\left(1-\mathrm{k}_{\text {surf }} \mathrm{f}_{\text {exp }}\right) \text { rhowater }+\mathrm{k}_{\text {surf }} \mathrm{f}_{\text {exp }} \text { rhosand }
$$

The value of $\mathrm{k}_{\text {surf }}$ is determined in the next section, where the density of the slurry is measured and the reflection coefficient determined in an experimental measurement. 


\subsection{Evaluation of the Surface Effect $\mathbf{k}_{\text {surf }}$}

The experimental apparatus to determine $\mathrm{k}_{\text {surf }}$ is shown in Figure 13. The transducer used in the Essayons measurement is epoxied to a block of A36 steel. A depression of $2 \mathrm{~mm}$ was machined in the steel directly above the 0.5 -in.-diameter transducer. A plastic tube having an inside diameter of 0.5 in. was placed in the depression and epoxied in place. Previously sand had been obtained during a visit to the Essayons while it was operating outside of Coos Bay, Oregon. This sand was used to form a very thick slurry of sand and water. The density of the sand slurry can be calculated because the masses of both components were obtained on a balance, accurate to four decimal places. A small amount of water was obtained using a pipette, which was checked to see that it performed correctly.

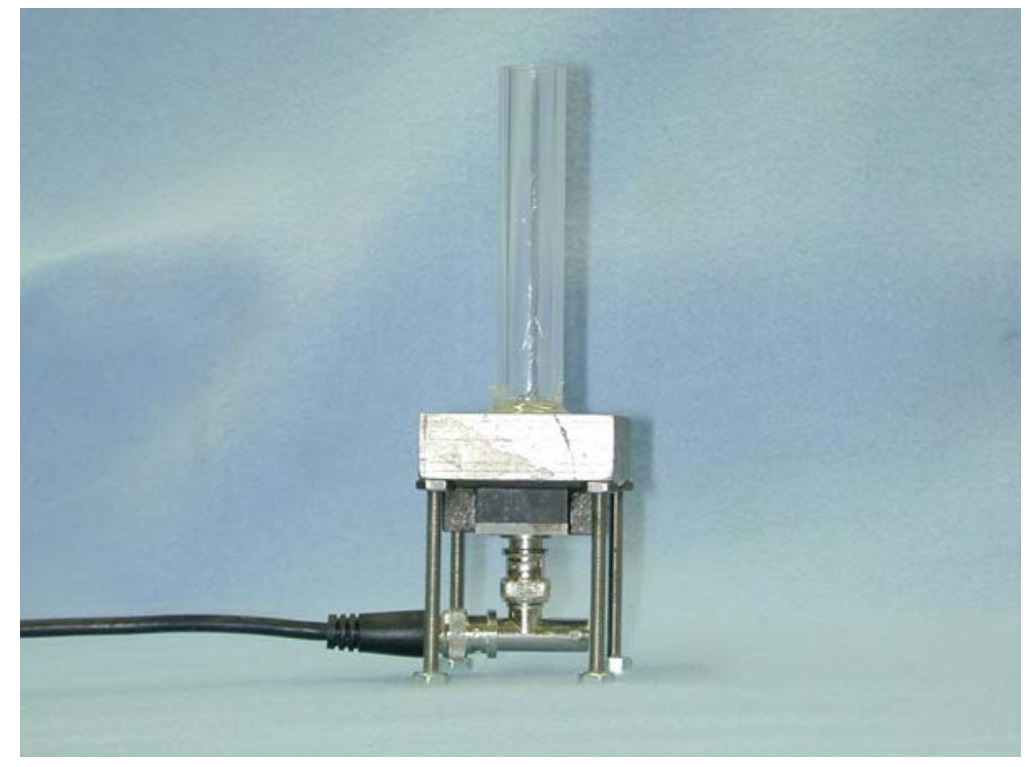

Figure 13. Surface Effect Apparatus

The objective of the measurement is to obtain $\mathrm{k}_{\text {surf }}$ by knowing the density and using the data acquisition code to determine $\mathrm{f}_{\text {exp }}$. The steps are as follows:

1. Use Eq. (13) to determine the fractional area $f$ of the sand, because the three values of density are known or measured. The properties of the sand-water slurry are shown in Table 4.

2. Set up the data acquisition code by running it in the calibration mode using water to find the values of $\mathrm{V}_{\text {water }}$ that are subsequently stored in a data file.

3. Run the data acquisition code for the slurry in the plastic tube to find the experimental value of the reflection coefficient. Substitute this value into the left side of Eq. (12). Because all other values are known (or can be calculated), the value of $\mathrm{f}$ can be obtained, and appropriately called $f_{\text {exp. }}$.

4. $\mathrm{k}_{\text {surf }}$ is defined as the ratio $\mathrm{f} / \mathrm{f}_{\exp }$ and is evaluated in Table 5 . 
Four sets of measurements are shown in Table 4.

Table 4. Properties of the Sand-Water Slurry

\begin{tabular}{lcccccc}
\hline $\begin{array}{c}\text { Trial } \\
\text { No. }\end{array}$ & $\begin{array}{c}\text { Mass of } \\
\text { Sand } \\
\text { (grams) }\end{array}$ & $\begin{array}{c}\text { Mass of } \\
\text { Water } \\
\text { (grams) }\end{array}$ & $\begin{array}{c}\text { Slurry } \\
\text { Density } \\
\left(\mathbf{g} / \mathbf{c m}^{\mathbf{3}}\right)\end{array}$ & $\begin{array}{c}\text { Height of } \\
\text { Slurry Column } \\
\mathbf{( c m )}\end{array}$ & $\begin{array}{c}\text { Sand } \\
\text { Fractional } \\
\text { Area f }\end{array}$ & $\begin{array}{c}\text { Water } \\
\text { Fractional } \\
\text { Area (1-f) }\end{array}$ \\
\hline 1 & 0.4868 & 0.20 & 1.775 & 0.31 & 0.4821 & 0.5179 \\
2 & 0.5356 & 0.22 & 1.775 & 0.34 & 0.4821 & 0.5179 \\
3 & 0.5118 & 0.21 & 1.776 & 0.32 & 0.4824 & 0.5176 \\
4 & 0.4007 & 0.10 & 1.973 & 0.20 & 0.6051 & 0.3949 \\
\hline
\end{tabular}

Table 5. Results from Running the Data Acquisition Code

\begin{tabular}{lcccc}
\hline $\begin{array}{c}\text { Trial } \\
\text { No. }\end{array}$ & $\mathbf{R C}_{\text {exp }}$ & $\mathbf{f}_{\text {exp }}$ & $\begin{array}{c}\text { Sand } \\
\text { Fractional } \\
\text { Area f }\end{array}$ & $\mathbf{k}_{\text {surf }}$ \\
\hline 1 & -0.90459 & 0.3331 & 0.4821 & 1.4470 \\
2 & -0.90237 & 0.3556 & 0.4821 & 1.3556 \\
3 & -0.89529 & 0.4274 & 0.4824 & 1.1287 \\
4 & -0.89137 & 0.4672 & 0.6051 & 1.2952 \\
\hline
\end{tabular}

The average value of $\mathrm{k}_{\text {surf }}$ and its standard deviation is $1.3066 \pm 0.1340$.

Comments and improvements on these measurements will be presented in a later section. 


\subsection{Summary of Measurements Obtained on July 9, 2009}

Three types of measurements were performed: (1) using the data acquisition code to measure the density, (2) recording of the density values from the radioactive sensor, and (3) recording the density and salinity of the seawater using the refractometer.

\subsection{Measurements with Data Acquisition System}

The first step in setting up the data acquisition code is to obtain a water or, here, a seawater calibration. The dredge was set to intake only seawater. The amplitudes of the echoes are obtained and recorded to a file. A data file is then obtained to measure the density of the seawater, using the seawater calibration file. The data acquisition system shows a graph similar to Figure 8 that has zero slope, which is expected. The system is then ready to measure the density of a slurry. Table 6 shows a summary of the data for the transducer of frequency $2.25 \mathrm{MHz}$ and diameter of 0.5 inches. The file ID contains the date and the time. Each run for the slurry contained 3000 values of the density. At the rate of 3 per second, this required about 17 minutes. For the last data set, the dredge was set to take only seawater again. This was to check that the seawater calibration was correct during the entire time, by again showing zero slope on a graph similar to Figure 8.

Table 6. Listing of Data Files

\begin{tabular}{ll}
\hline \multicolumn{1}{c}{ File ID } & \multicolumn{1}{c}{ Measurement Type } \\
\hline 09791146 & Seawater Calibration \\
0979120 & Seawater vs. seawater calibration \\
0979133 & Density of sand slurry \\
09791524 & Density of sand slurry \\
09791613 & Density of sand slurry \\
09791759 & Less efficient dredging of sand slurry \\
09791912 & Seawater vs. initial seawater calibration \\
\hline
\end{tabular}

\subsection{Density Measurements Using Radioactive Sensor}

Density measurements of the radioactive sensor were recorded on the Bridge and some results are shown in Figure 14. The density of $1.11 \mathrm{~g} / \mathrm{cm}^{3}$ was obtained during the seawater calibration for data file 09791146. This density is larger than expected for seawater, which is about $1.025 \mathrm{~g} / \mathrm{cm}^{3}$. Either the radioactive sensor is reading high or the values are correct, and the seawater calibration must be adjusted. In the next section, we shall assume that the radioactive sensor is reading correctly. 


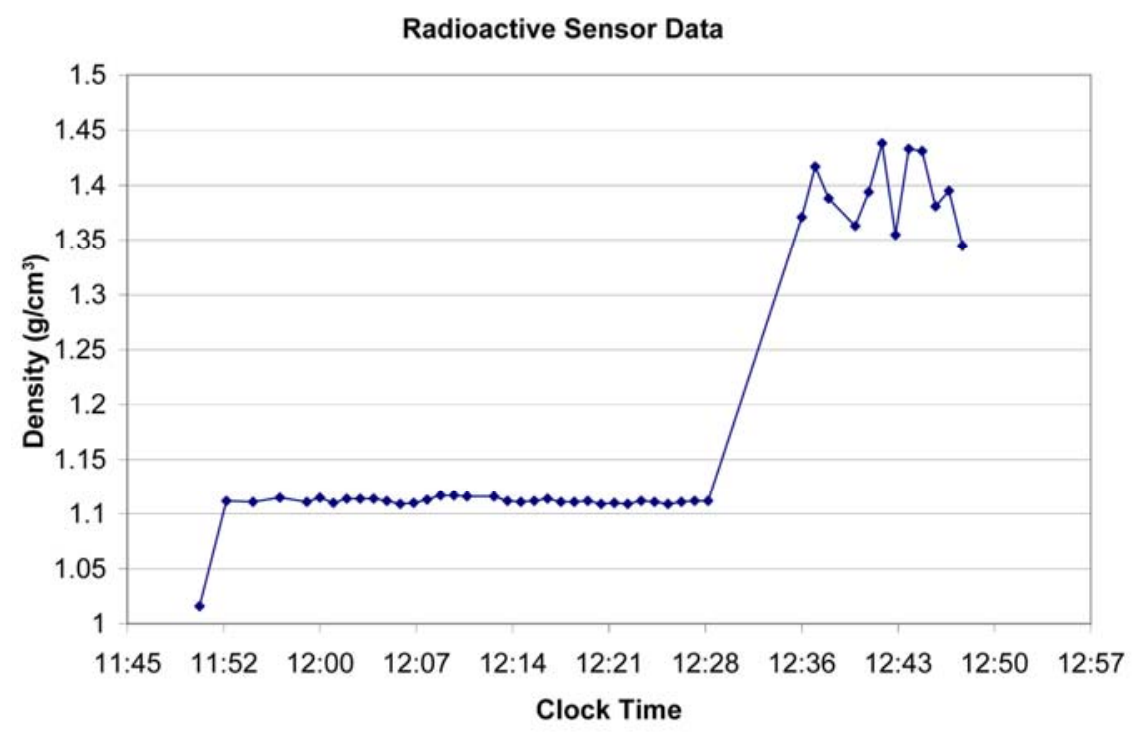

Figure 14. Data Obtained from the Radioactive Sensor as a Function of Time

\subsection{Refractometer Measurements}

Two measurements were taken using the refractometer. At 9:30 am on July 9, the refractometer reading gave a density value of $1.004 \mathrm{~g} / \mathrm{cm}^{3}$ with a salinity of $5 \%$, which is obviously very close to that fresh water. However, at $1: 39 \mathrm{pm}$ the density reading was $1.021 \mathrm{~g} / \mathrm{cm}^{3}$ with a salinity of $29 \%$. Additional comments about this change will be presented in the next section. 


\subsection{Analysis of the Essayons Density Data}

The data acquisition code for the seawater calibration, 09791146, stores a file for $\mathrm{V}_{\text {water }}$ ( or $\mathrm{V}_{\text {seawater }}$ ), which lists the amplitude for each echo for seawater. The code used values for the density of seawater as $1025 \mathrm{~kg} / \mathrm{m}^{3}\left(1.025 \mathrm{~g} / \mathrm{cm}^{3}\right)$ and a velocity of $1531 \mathrm{~m} / \mathrm{s}$. Assuming that the correct value of the density of the calibration liquid is $1110 \mathrm{~kg} / \mathrm{m}^{3}$, as shown by the data in Figure 14, the density values for the sand slurry must be recalculated. Figure 8 shows the data obtained for $\ln \left(\mathrm{V}_{\text {slurry }} / \mathrm{V}_{\text {water }}\right)$ versus the echo number for one data point in file 0979133 for the sand slurry. The slope of this line -0.01323 is correct, but the reflection coefficient must be recalculated. That is, in Eq. (7) the $\mathrm{RC}_{\text {water }}$ is written for the case in which the calibrating liquid is water. This equation can be rewritten as:

$$
\mathrm{RC}_{\text {exp }}=\mathrm{RC}_{\text {calibliq }} \mathrm{e}^{\text {slope }} \text {, }
$$

where $\mathrm{RC}_{\text {calibliq }}$ is for a calibration liquid with a density of $1110 \mathrm{~kg} / \mathrm{m}^{3}$. The temperature of the seawater was recorded to be $60.5^{\circ} \mathrm{F}$. To calculate the acoustic impedance, the velocity of sound in the calibration liquid is required and was taken to be $1505 \mathrm{~m} / \mathrm{s}$. The calculation of $\mathrm{RC}_{\text {calibliq }}$ is carried out in Table 7 .

Table 7. Parameter Calculations

\begin{tabular}{|l|l|l|}
\hline Line & \multicolumn{1}{|c|}{ Parameter } & \multicolumn{1}{c|}{ Value } \\
\hline 1 & Density of calibration liquid & $1110 \mathrm{~kg} / \mathrm{m}^{3}$ \\
\hline 2 & Velocity of sound in calibration liquid & $1505 \mathrm{~m} / \mathrm{s}$ \\
\hline 3 & Acoustic impedance of calibration liquid & $1110 \times 1505=1.6706 \times 10^{6} \mathrm{~kg} / \mathrm{m}^{2} \mathrm{~s}$ \\
\hline 4 & Density of steel & $7841.2 \mathrm{~kg} / \mathrm{m}^{3}$ \\
\hline 5 & Velocity of sound in steel & $5875.3 \mathrm{~m} / \mathrm{s}$ \\
\hline 6 & Acoustic impedance of steel & $7841.2 \times 5875.3=46.069 \times 10^{6} \mathrm{~kg} / \mathrm{m}^{2} \mathrm{~s}$ \\
\hline 7 & $\begin{array}{l}\text { Reflection coefficient from steel-calibration liquid } \\
\text { interface }\end{array}$ & $(1.6706-46.069) /(1.6706+46.069)=-0.93001$ \\
\hline 8 & RCstwtr at $12.7^{\circ} \mathrm{C}$ & -0.9388 \\
\hline 9 & RCwtrsand at $12.7^{\circ} \mathrm{C}$ & +0.8180 \\
\hline 10 & Tstwtr at $12.7^{\circ} \mathrm{C}$ & 0.0612 \\
\hline 11 & Twtrst at $12.7^{\circ} \mathrm{C}$ & 1.9388 \\
\hline 12 & Fractional area $\mathrm{f}_{\text {exp }}$ of sand (Eq. 19) & $\left(\mathrm{RC} \mathrm{exp}_{\text {exp }}+0.9388\right) / 0.097059$ \\
\hline
\end{tabular}

To illustrate how the calculation of the density of the sand slurry is performed in the recalculation, four data points from file 0979133 are chosen - two with negative slope (as expected) and two with positive slope. The steps in the recalculation are shown in Table 8. The first column lists the J value for the data point and the second column lists the slope that was obtained by the data acquisition code. The third column shows the results of the calculation of $\mathrm{RC}_{\exp }$ using Eq. (17) with $\mathrm{RC}_{\text {calibliq }}$ equal to -0.9300 (a value obtained in Table 7). 
Table 8. Calculation of the Density of Sand Slurry for File 0979133

\begin{tabular}{|c|c|c|c|c|c|}
\hline J value & Slope & $\mathbf{R C}_{\exp }$ & $\mathbf{f}_{\exp }$ & f eff & $\begin{array}{c}\text { rhoslurry } \\
\left(\mathbf{k g} / \mathbf{m}^{3}\right)\end{array}$ \\
\hline 655 & -0.0132 & -0.9178 & 0.2162 & 0.3115 & 1500 \\
\hline 91 & -0.0094 & -0.9213 & 0.1797 & 0.2589 & 1416 \\
\hline 225 & +0.0027 & -0.9325 & 0.0646 & 0.0931 & 1148 \\
\hline 281 & +0.0064 & -0.9359 & 0.0291 & 0.0419 & 1066 \\
\hline
\end{tabular}

In the recalculation, we shall consider a sand-fresh water slurry, rather than sand-seawater slurry. There are several reasons for this. During the data acquisition, a thermocouple was attached to the outside of the pipeline wall and the temperature was recorded on the data file. The velocity of sound in fresh water is known very well as a function of temperature (Povey 1997), and is given by:

$$
\begin{aligned}
\mathrm{v}_{\text {water }} & =1402.39+5.03711 \mathrm{~T}-0.0580852 \mathrm{~T}^{2}+3.3420 \\
& \times 10^{-4} \mathrm{~T}^{3}-1.47800 \times 10^{-6} \mathrm{~T}^{4}+3.14632 \times 10^{-9} \mathrm{~T}^{5}
\end{aligned}
$$

The velocity of sound in water was calculated in $\mathrm{m} / \mathrm{s}$ using the temperature $\mathrm{T}$ in ${ }^{\circ} \mathrm{C}$ recorded on the data file. A second reason is that the refractometer readings showed that the density of the seawater changed from fresh water initially to salty water at a later time.

The next step is to find the fractional area $f_{\text {exp }}$ of sand using Eq. (12) and solving for the value of $f_{\text {exp }}$ :

$$
\mathrm{f}_{\text {exp }}=\left(\mathrm{RC}_{\text {exp }}-\mathrm{RCstwtr}\right) /(\text { Tstwtr RCwtrsand Twtrst })
$$

In Table 2, these terms are defined and evaluated for the velocity of sound in water of $1482 \mathrm{~m} / \mathrm{s}$. For file 0979133 , the temperature is $12.76^{\circ} \mathrm{C}$ and, using Eq. (18), the velocity of sound is $1457.9 \mathrm{~m} / \mathrm{s}$. These terms are defined in Table 7 for the velocity of $1457.9 \mathrm{~m} / \mathrm{s}$. These terms are substituted into Eq. (19) so that $\mathrm{f}$ is given in terms of $\mathrm{RC}_{\text {exp }}$ and constants as shown in line 12 of Table 7.

As discussed earlier for the surface effects, the effective value of the fractional area of sand is given by:

$$
\mathrm{f} \text { eff }=\mathrm{k}_{\text {surf }} \mathrm{f}_{\text {exp }}
$$

The value of $\mathrm{k}_{\text {surf }}$ is given earlier as $1.3066 \pm 0.1340$. The value of the upper limit, 1.441 , will be used in the calculation of the density of the slurry, given by:

$$
\text { rhoslurry }=(1-\text { f eff }) \text { rhowater }+ \text { f eff rhosand }
$$

where rhowater $=998 \mathrm{~kg} / \mathrm{m}^{3}$ and rhosand $=2610 \mathrm{~kg} / \mathrm{m}^{3}$. Table 8 shows the calculation of the density of the slurry for four data points in file 0979133. The values of the slope for these points can be seen in Figure 3 and the recalculated density values in Figure 1. The effect of the positive slope is also shown in Table 8 , where, for $\mathrm{J}=281$, the density is less than that of the calibration liquid, $1110 \mathrm{~kg} / \mathrm{m}^{3}$. For $\mathrm{J}=225$, the slurry density is very close to that of the calibration liquid. For negative slopes, the slurry density is 
greater than that of the calibration fluid. These calculations provide an understanding of the basic data for the slopes shown in Figure 3.

The average value of the slurry density is obtained by subdividing the 3000 data points into segments and obtaining the average value of the density for the points in each segment. Figure 2 shows the results of using six segments. However, if the number of points in a segment is smaller, there is more spread in the average values, as shown in Figure 15 for 60 segments and 30 segments.

The average value of the slurry density is affected by the value of $\mathrm{k}_{\text {surf. }}$. At present, the uncertainty in $\mathrm{k}_{\text {surf }}$ is about $\pm 10 \%$. The results of increasing $\mathrm{k}_{\text {surf }}$ to 2.0 is shown in Figure 16. It is, of course, very important in future studies to reduce the uncertainty in $\mathrm{k}_{\text {surf. }}$.

The results for the data file 09791544 are shown in Figure 17 and Figure 18 for the average value of the density in each segment. Figure 18 shows the slurry density when the efficiency of the dredging operation was reduced for data file 09791759. Comparison with Figure 1 shows the significant change that occurred and was detected by the PNNL density sensor. 


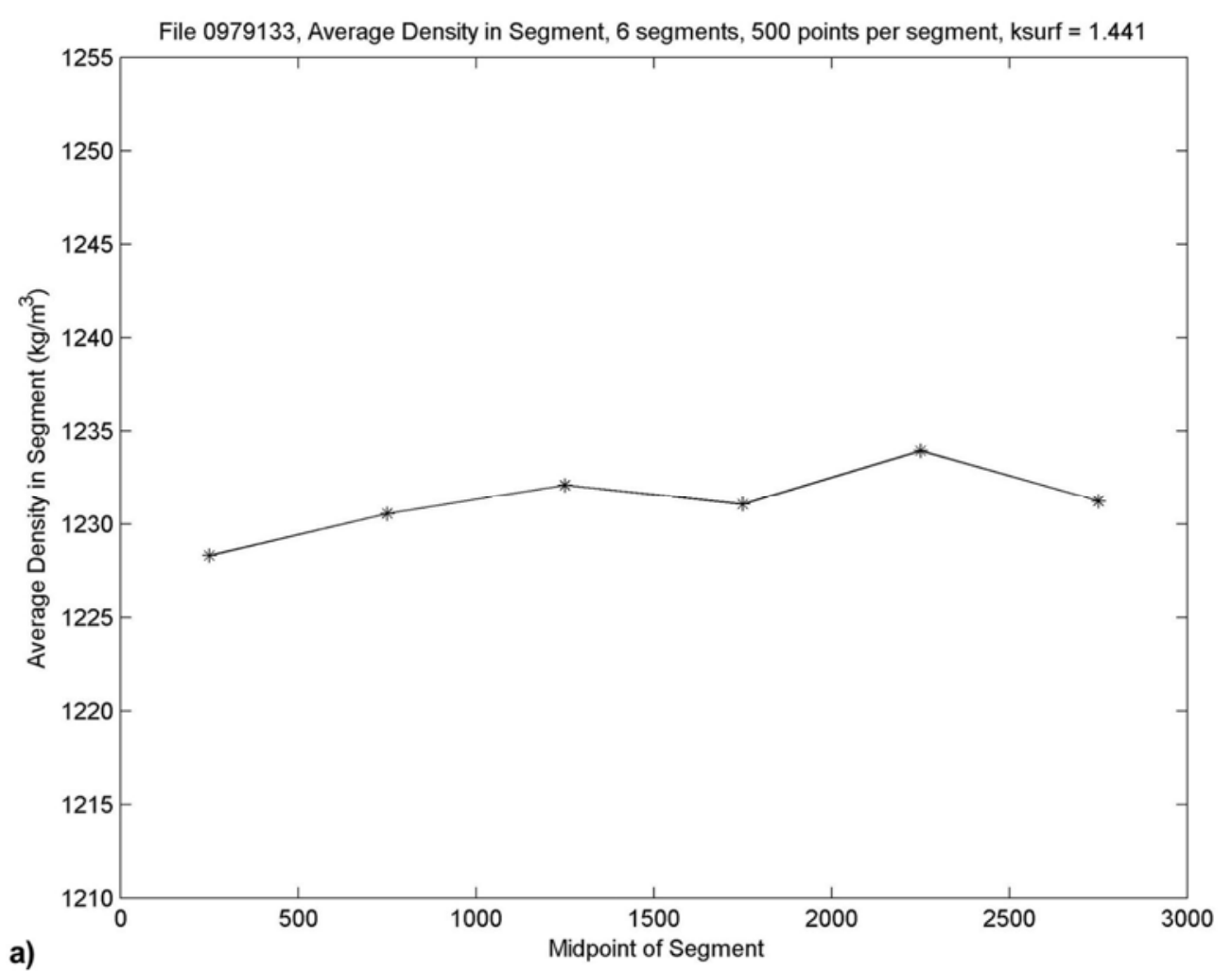

a)

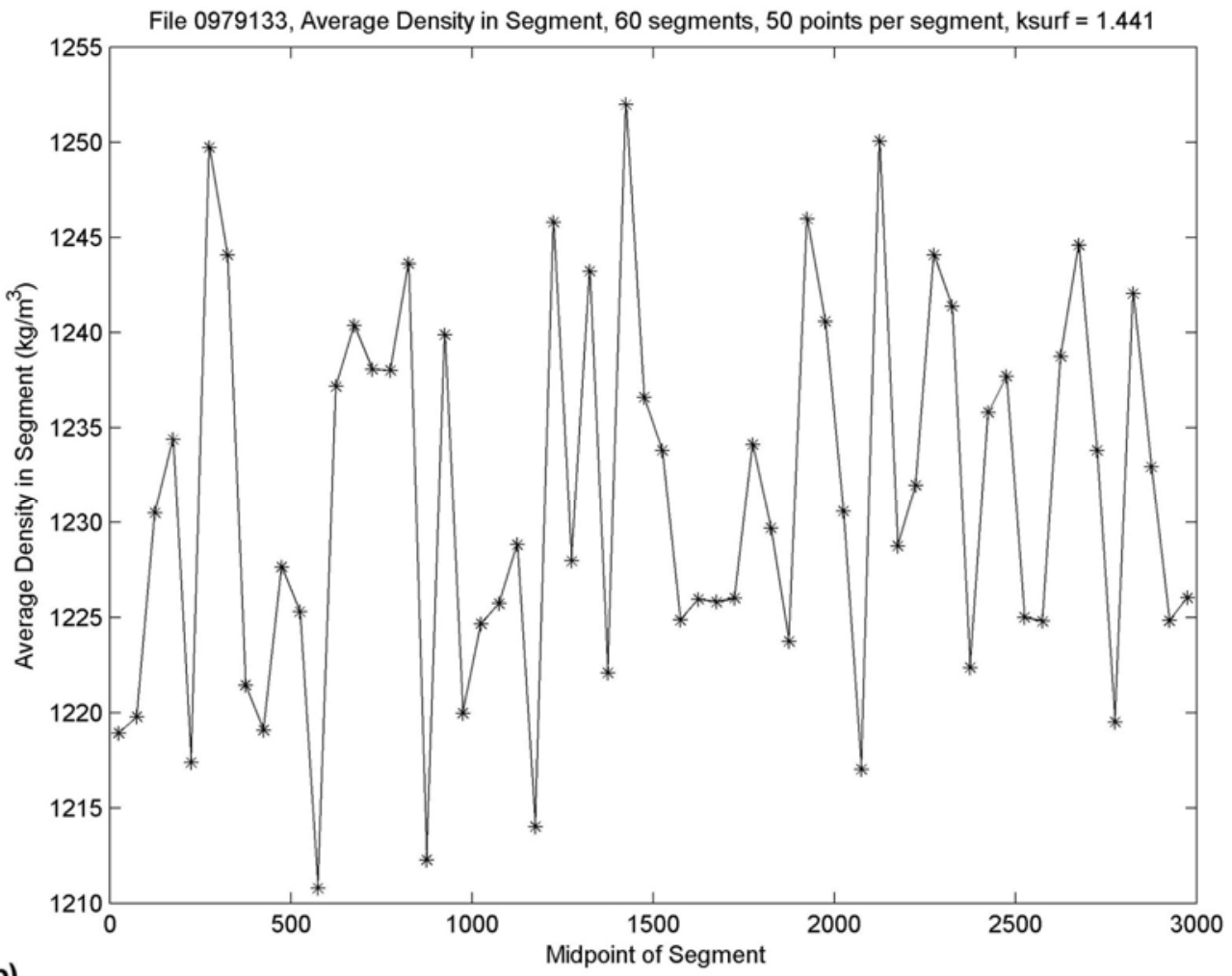

b)

Figure 15. Average Values Obtained by Dividing 3000 Values into Various Segments and Calculating the Average Density in Each Segment: a) 6 Segments and b) 60 Segments 


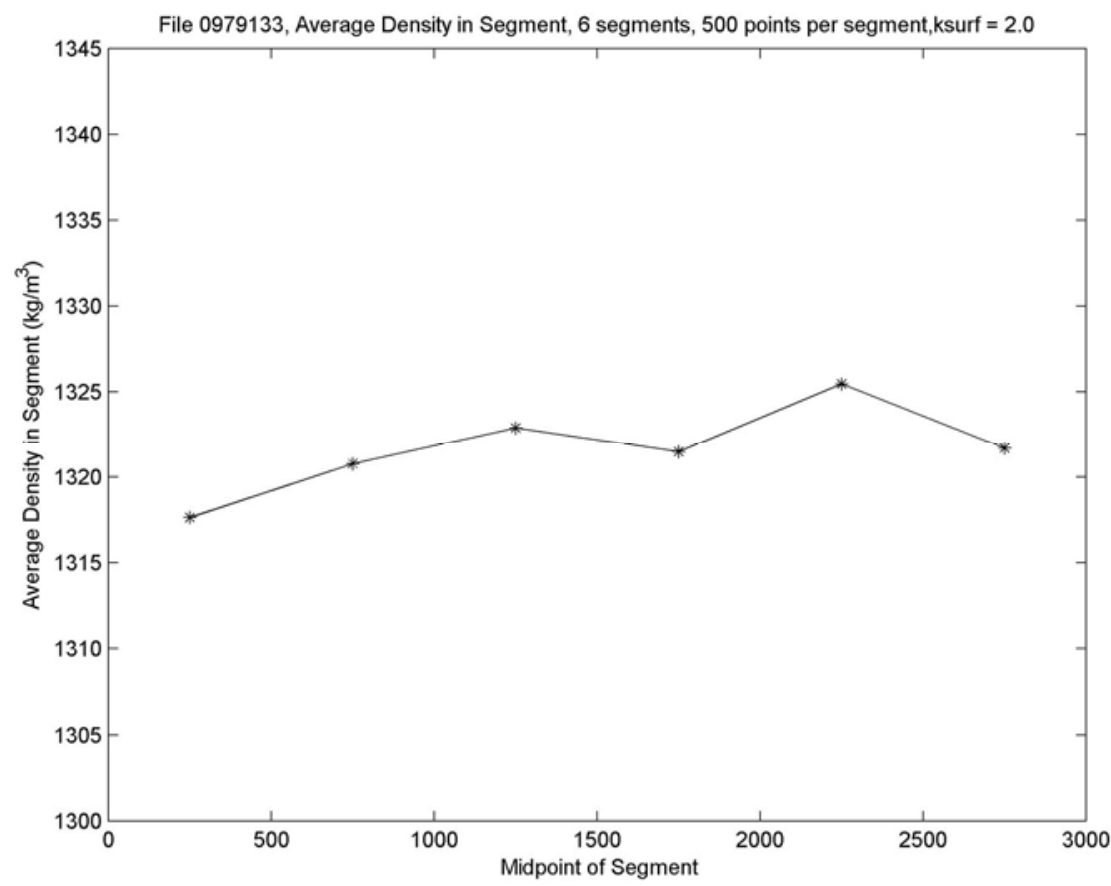

Figure 16. Average Value of the Density Obtained by Dividing the 3000 Values into 6 Segments and Using $\mathrm{k}_{\text {surf }}$ Equal to 2.0

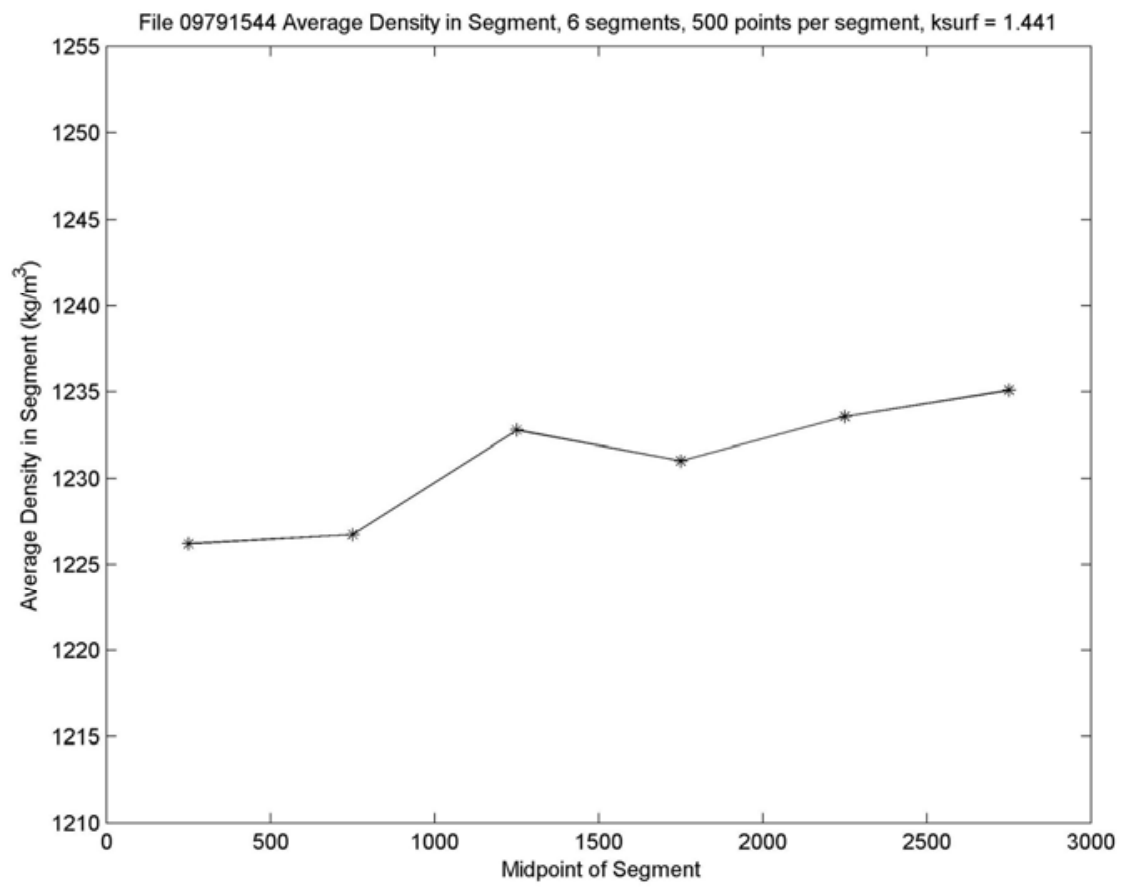

Figure 17. Average Value of the Density for 6 Segments Using File 09791544 


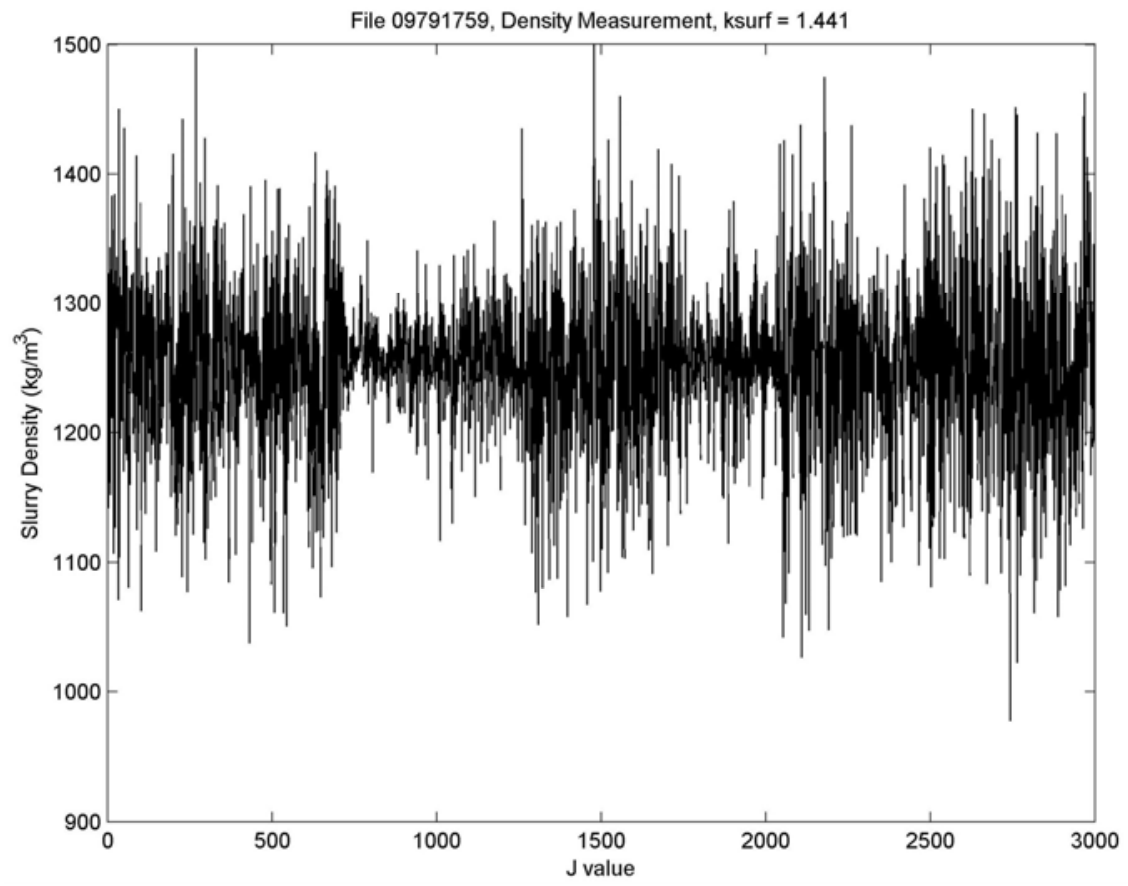

Figure 18. Slurry Density When Dredging Efficiency was Reduced for File 09791759 


\subsection{Discussion of Results and Needs for Future Development}

\subsection{Calibration Liquid}

These results show the great importance of precise knowledge of the calibration fluid. Initially, the calibration aboard the Essayons was taken to be seawater. But the radioactive density sensor gave a value of $1.11 \mathrm{~g} / \mathrm{cm}^{3}$. This value is probably due to some small amount of sand mixed with the seawater. The recalculation used this value, but the actual value of the velocity of sound in the actual calibration liquid was unknown and so a reasonable value was used for it. This, of course, leads to an uncertainty in the slurry density measurement.

Calibration using air is highly desirable because $100 \%$ of the ultrasound reflects from air and, thus, the reflection coefficient is -1 . This has been measured in the lab also, by first calibrating with water and then using only air in contact with the steel surface. A reflection coefficient of -0.998 was routinely measured.

While on the Essayons, the calibration with air was discussed, but is seems that sometimes, the water still remains in the pipeline. This needs to be investigated further, because the use of air is so simple.

If the use of air as a calibration is not feasible, then the properties of the base liquid in which the sand is immersed must be measured. This is discussed next.

\subsection{Measurement of the Properties of the Base Liquid}

The measurements with the refractometer showed that in the morning the base liquid was very nearly fresh water and in the afternoon, salt water. This was due to the effect of tides in the mouth of the Columbia River. It is proposed to measure the density and velocity of sound of the base liquid using a second sensor, illustrated in Figure 19, and the same data acquisition system as is used to measure the density of the sand slurry. The second transducer can be surrounded by a stainless steel shell and the transducer affixed to the stainless steel front plate having a thickness of about 0.375 inches. The multiple reflections would be measured within this plate and yield the acoustic impedance of the liquid. The velocity of sound in the liquid can be obtained by measuring the signal from a plate a short distance away, about 2 inches. The acoustic impedance divided by the velocity of sound yields the density. The coding for the density sensor is already complete and data have been published using this technique for liquids (Bamberger and Greenwood 2004).

This second sensor needs to be placed so that it can observe the liquid from the dredged slurry, BUT the sand must be settled out first. This sensor can be calibrated using air. A mechanical engineer can design a system that accomplishes these goals and is automatic. Some discussion on this development is, of course, needed.

A cable connects the transducer in this sensor to the data acquisition system. The data acquisition system has a computer-controlled multiplexer, which is essentially a switching system that switches the electronics from the transducer in the pipeline wall to the transducer measuring the properties of the base liquid. For example, there might be options in the final code measuring the properties of the base liquid. 


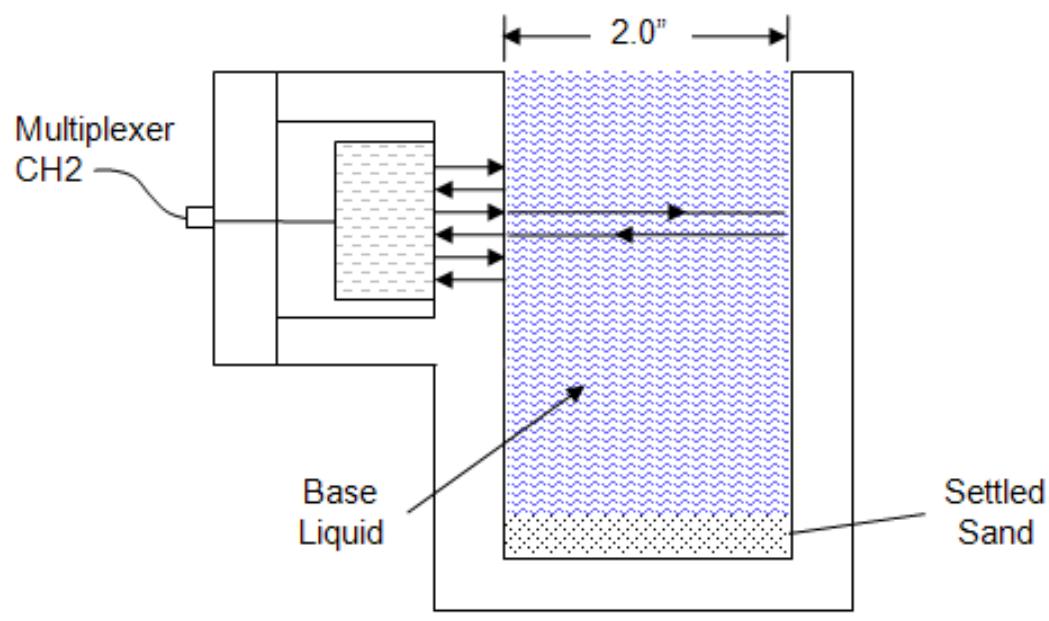

Figure 19. Schematic Diagram of Base-Liquid Sensor for Measuring the Density and Velocity of Sound in the Base Liquid

\subsection{Evaluating the Constant $\mathbf{k}_{\text {surf }}$}

The results for the evaluation of $\mathrm{k}_{\text {surf }}$ are shown in Table 5 and the average value of $\mathrm{k}_{\text {surf }}$ is $1.3066 \pm$ 0.1340 . This is a standard deviation of about $\pm 10 \%$. The data were obtained by placing sand in the tube and mixing water with the sand. The precise amount of water to add was a difficult decision. Even though the first three trials in Figure 4 have very close values of the density, the values of $\mathrm{RC}_{\exp }$ from running the data acquisition code vary somewhat, as shown in column 2 of Table 5. The problem occurs because the reflection coefficient for water is subtracted from $\mathrm{RC}_{\text {exp }}$. Subtraction can lead to large errors if there is uncertainty in the two values, as occurs here. Thus, the value of $\mathrm{k}_{\text {surf }}$ ranges from 1.13 to 1.45 for the first three trials. The conclusion is that another method is needed to determine $\mathrm{k}_{\text {surf. }}$

One method is to use a less-dense slurry in a small volume and stirs the small volume with either a magnetic stirrer or a mechanical stirrer in the base. The transducer attached to the steel plate, similar to the tube setup, would remain. The temperature of the water used for calibration will be measured, so that the velocity of sound at that temperature can be determined. Repeatable measurements for $\mathrm{RC}_{\text {exp }}$ are expected for this setup. Data can be obtained for several values of the slurry density to ensure that $\mathrm{k}_{\text {surf }}$ remains constant, as expected.

Another method is to use the radioactive sensor and the ultrasonic sensor at the same time. Using a large number of data points in a segment, the two density values can be obtained and the value of $\mathrm{k}_{\text {surf }}$ determined. Once the value of $\mathrm{k}_{\text {surf }}$ is obtained for that location, the radioactive sensor can be decommissioned.

The value of $\mathrm{k}_{\text {surf }}$ will be different for a sand slurry than for mud, for example. However, the radioactive sensor has different absorption coefficients in different locations, as well. 


\subsection{Temperature Effects}

The acoustic impedance of steel was used in the calculation of the slurry density. The density of the A36 steel used in the laboratory measurements was obtained in the usual way. The velocity of sound was measured at room temperature by measuring the thickness of the steel and measuring the time between two adjacent echoes. The effect of temperature on the velocity of sound in steel was not investigated, and it is simply easier to measure it over the range of $10^{\circ} \mathrm{C}$ to $20^{\circ} \mathrm{C}$. This can be easily measured in the lab to see how much effect there is and use the one at the most likely temperature. However, a greater accuracy can be obtained by measuring it in the lab as a function of temperature. In the Essayons measurements, a thermocouple was affixed to the pipeline wall and the data acquisition system measured the temperature.

\subsection{Average Value of the Slurry Density}

Figure 15 shows the effect of using a different number of data points in the averaging process. Figure 15a, which averaged 500 points, shows much less deviation in the average density value. At the rate of 3 density values per second, the accumulation of 500 points would take 2.8 minutes; 100 points, 0.6 minutes. This is probably too long a time between submitting data points to the ship's data acquisition system. However, there is a solution to this situation.

The data acquisition system for the Essayons obtained data in the following way. The signal is acquired by the digitizer card in 0.06 seconds, by using the clock function in the code just before the signal acquisition and after the signal acquisition. A density value is then obtained about 0.27 seconds later (total time of 0.33 seconds) in a serial or sequential operation. The computer has two processors. The code could be written to take the data in parallel. That is, one processor could acquire the data (say 250 points) and the second processor could analyze the data, while the data is being acquired by the first processor. There would also be significant time saving in using a matrix of 250 points to obtain a density matrix of 250 points, rather than computing the density value for each signal, as the code does now.

The comparison of the data from the ultrasonic sensor with that from the radioactive sensor is shown in Figure 2. Very good agreement results when the value of $k_{\text {surf }}$ is equal to 2.2. This is not an unreasonable expectation for the value from the proposed experiment, given the \pm 10 percent uncertainty in the initial measurement and the increased accuracy for the proposed measurement of $\mathrm{k}_{\text {surf. }}$. In conclusion, once the improvements described in this section have been made, the performance of the PNNL density sensor will compete very favorably with that of the radioactive sensor. 


\subsection{References}

Bamberger JA and MS Greenwood. 2004. "Measuring Fluid and Slurry Density and Solids Concentration Non-Invasively." Ultrasonics 42:563-567.

Greenwood MS and JA Bamberger. 2004. "Self-calibrating Sensor for Measuring Density through Stainless Steel Pipeline Wall.” Journal of Fluids Engineering-Transactions of the ASME 126:189-192.

Krautkrämer J and H Krautkrämer. 1990. Ultrasonic Testing of Materials, 4th fully revised Edition. Springer-Verlag, New York.

Povey MJ. 1997. Ultrasonic Techniques for Fluids Characterization. Academic Press, San Diego, California. p. 31. 


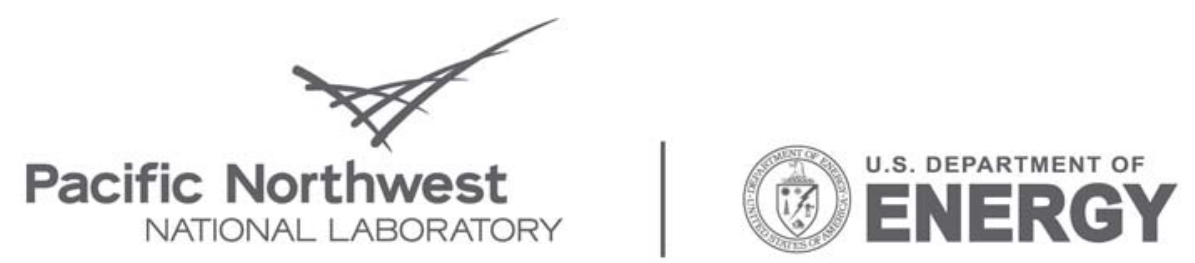

Proudly Operated by Battelle Since 1965

902 Battelle Boulevard

P.O. Box 999

Richland, WA 99352

1-888-375-PNNL (7665)

www.pnl.gov 